\title{
Gill proteome networks explain energy homeostasis during salinity stress in Oreochromis mossambicus
}

\author{
Larken Root ${ }^{1}$ and Dietmar Kültz ${ }^{1}$ \\ ${ }^{1}$ University of California Davis
}

February 8, 2022

\begin{abstract}
Acclimations of Oreochromis mossambicus to elevated salinity were conducted with multiple rates of salinity increase and durations of exposure to determine the rate-independent maximum salinity limit and the incipient lethal salinity. Quantitative proteomics of over 3000 gill proteins simultaneously was performed to analyze molecular phenotypes associated with treatments representative of key zones in the salinity-level $\mathrm{x}$ duration matrix. For this purpose, a species- and tissue-specific data-independent acquisition (DIA) assay library of MSMS spectra was created. From these DIA data, protein networks representing complex molecular phenotypes associated with salinity acclimation were generated. Organismal performance indicators of salinity tolerance were then correlated with salinity-regulated protein networks. O. mossambicus was determined to have a wide "zone of resistance" from approximately $75 \mathrm{~g} / \mathrm{kg}$ salinity to $120 \mathrm{~g} / \mathrm{kg}$, which fish survive for a limited period with eventual loss of function. Crossing the critical threshold salinity into the zone of resistance corresponds with blood osmolality increasing beyond $400 \mathrm{mOsm}$, significantly reduced body condition factor, and cessation of feeding. Gill protein networks impacted at extreme salinity levels both above and below the critical salinity threshold include increased energy metabolism, especially upregulation of electron transport chain proteins, and regulation of specific osmoregulatory proteins. Cytoskeletal, cell adhesion, and extracellular matrix proteins are enriched in regulation network patterns that are sensitive to the critical salinity threshold. Network analysis of these patterns provides deep insight into specific mechanisms of energy homeostasis during salinity stress.
\end{abstract}

Title: Gill proteome networks explain energy homeostasis during salinity stress in Oreochromis mossambicusAuthors: Larken Root ${ }^{1}$ and Dietmar Kultz ${ }^{1}$ Author affiliations: ${ }^{1}$ Department of Animal Sciences, University of California Davis, Meyer Hall, One Shields Avenue, Davis, CA 95616, USAKeywords: quantitative proteomics, DIA assay library, systems biology, fish gill, mass spectrometry, osmoregulationRunning head: Gill proteome networks in tilapia

Corresponding author:dkueltz@ucdavis.edu

Abstract:

Acclimations of Oreochromis mossambicus to elevated salinity were conducted with multiple rates of salinity increase and durations of exposure to determine the rate-independent maximum salinity limit and the incipient lethal salinity. Quantitative proteomics of over 3000 gill proteins simultaneously was performed to analyze molecular phenotypes associated with treatments representative of key zones in the salinity-level $\mathrm{x}$ duration matrix. For this purpose, a species- and tissue-specific data-independent acquisition (DIA) assay library of MSMS spectra was created. From these DIA data, protein networks representing complex molecular phenotypes associated with salinity acclimation were generated. Organismal performance indicators of salinity tolerance were then correlated with salinity-regulated protein networks. O. mossambicus was determined to have a wide "zone of resistance" from approximately $75 \mathrm{~g} / \mathrm{kg}$ salinity to $120 \mathrm{~g} / \mathrm{kg}$, which fish survive for a limited period with eventual loss of function. Crossing the critical threshold salinity into the zone of resistance corresponds with blood osmolality increasing beyond $400 \mathrm{mOsm}$, significantly reduced body 
condition factor, and cessation of feeding. Gill protein networks impacted at extreme salinity levels both above and below the critical salinity threshold include increased energy metabolism, especially upregulation of electron transport chain proteins, and regulation of specific osmoregulatory proteins. Cytoskeletal, cell adhesion, and extracellular matrix proteins are enriched in regulation network patterns that are sensitive to the critical salinity threshold. Network analysis of these patterns provides deep insight into specific mechanisms of energy homeostasis during salinity stress.

\section{Introduction:}

Abiotic factors are key in determining the extent of suitable habitat for teleost fish (Somero, G., Lockwood, B., Tomanek, L., 2016). Fish living in freshwater and brackish systems often have limited migration options due to geographic constraints. Habitat shifts include exploration of areas that vary in salinity, e.g., brackish coastal areas and salt lakes. Euryhaline tilapia species regularly occupy freshwater environments but these fish also venture into extremely hypersaline habitats which can exceed $100 \mathrm{~g} / \mathrm{kg}$ in salinity (Panfili et al., 2004; Whitfield et al., 2006). Adaptations that enable euryhaline fish to explore such habitats also improve tolerance to other stressors (Elliott \& Quintino, 2007). Holistic systems level approaches can be utilized to identify molecular and organismal phenotypes to habitat tolerance adaptations.

Salinity tolerance under relevant ecological conditions is dependent on the level of salinity of exposure, the rate of salinity increase, the ionic composition of saline water, and time spent at high salinity. Acute salinity challenges involving direct transfer are common in environmental physiology research (Amoudi et al., 1996; Fuadi et al., 2021; Iwama et al., 1997; Kammerer et al., 2010), but acute salinity tolerance is often less than the salinity to which a fish can acclimate over time and may not represent a common salinity challenge fish have evolved to survive. For example, O. mossambicus cannot survive direct transfer to seawater (SW), which has a standard salinity of $35 \mathrm{~g} / \mathrm{kg}$ (Lewis \& Perkin, 1978), but can be experimentally acclimated to several times SW salinity, while O. niloticus has similar capacity for direct transfer salinity tolerance as O. mossambicusbut cannot acclimate to salinity levels greater than SW (Avella et al., 1993; Basiao et al., 2005; Ronkin et al., 2015). Researchers have used survival at different lengths of time from days to weeks as indicatory of long term survival (Blackburn, 1987; Christensen et al., 2019; Langston et al., 2010; Schultz \& McCormick, 2012; Watanabe et al., 1985), despite evidence that degeneration of biological function and mortality can occur in Oreochromis species following extended periods in hypersaline conditions (Sardella, 2004).

Energy homeostasis theory provides a framework for understanding the relationship between the intensity of a stress and the duration of exposure using a three-tiered system of biological function. Within the "optimum" range of an environmental parameter a basal amount of energy is required to maintain internal homeostasis (Sokolova et al., 2012). In the "pejus" range, energy demand increases linearly with the stress to maintain homeostasis and manage the impacts of stress-related macromolecular damage, while the "pessimum" range is reached when energy expenditure and macromolecular damage increase in a non-linear relationship with the stress until loss of biological function (death). The boundary between pejus (zone of tolerance) and pessimum (zone of resistance) ranges is called the "critical threshold" or the incipient lethal level (Brett, 1956). Salinity levels in the pejus range are tolerable in the long term but result in reduced reproduction and/or growth due to reduced free energy, whereas exposure to pessimum range salinity is temporarily survivable but fish cannot increase energy expenditure sufficiently to maintain homeostasis, eventually resulting in death if conditions do not improve (Sokolova et al., 2012). Reaching the endpoint of biological function, called the Critical Salinity Maximum ( $\mathrm{CS}_{\mathrm{MAX}}$ ), will occur some period of time after crossing the critical salinity threshold. Energy homeostasis theory was developed predominantly using thermal stress response (Pörtner, 2010), in which case the critical threshold is defined physiologically by a transition to partial anaerobic metabolism. However, it is not clear if this indicator is applicable to salinity stress because the relationship between salinity and dissolved oxygen concentration is less direct than for temperature. Physiological indicators of fish transitioning from pejus to pessimum salinity ranges are undefined but crucial to assess the threat of salinity change on natural populations.

Whole organism measurements can describe the physiological state of a fish, but understanding the mecha- 
nisms of acclimation requires tissue-specific analysis of the interactions of molecular components. Proteomic analysis is a particularly promising approach for this purpose because proteins are linked directly to specific genomic loci via their accession numbers (Keerthikumar \& Mathivanan, 2017). Proteins define the structures and enact the majority of biochemical processes of each level of biological function (Ebhardt et al., 2015), and are thus the primary source of phenotypic variability which enables natural selection (Clarke, 1971; Mularoni et al., 2010). Careful choice of environmental challenges and time points allow the capture of relevant snapshots of protein signatures, which provide systems-level insight of organismal adaptation to maintain biological function (Kültz et al., 2007, 2016). In the current study, Data-Independent Acquisition Liquid Chromatography Mass Spectrometry (DIA-LCMS2) was used to capture gill protein signatures at key points in the salinity-level $\mathrm{x}$ duration matrix and identify biochemical networks that are indicative of adaptation in the pejus and pessimum ranges. The gill epithelium is particularly important for supporting organismal salinity tolerance of fish in addition to its critical role for respiration, acid-base regulation, and nitrogenous waste excretion (Sardella \& Brauner, 2007).

\section{Methods:}

\section{Challenges to Morbidity Point and two-week acclimation}

All experimental procedures were conducted with the approval of the UC Davis IACUC under protocols 20007 and 21846. Two adult Oreochromis mossambicus female-male pairs were bred, and fertilized eggs incubated in separate tanks. Following hatch, fish were raised for 6 months before the start of acclimation experiments, and all acclimations were begun before the fish were eight months post-hatch. Fish were kept in a 200L tank system in dechlorinated Davis, California tap water, which has been previously described (Fiol et al., 2011) and has a salinity less than $0.5 \mathrm{~g} / \mathrm{kg}$. Four distinct acclimation protocols were used in this study including; (1) gradual increase in salinity from FW with increases occurring once every 24 hours up to the Morbidity Point (MP) at five different rates of change per day $(32,24,12,8$, and $6 \mathrm{~g} / \mathrm{kg} /$ day), (2) increase from FW to target salinity level $(85,95$, and $105 \mathrm{~g} / \mathrm{kg})$ at a rate of $6 \mathrm{~g} / \mathrm{kg} /$ day followed by continuous exposure at constant salinity until MP, (3) acclimation from FW to the target salinity at different rates to achieve the target salinity after 14 days with four target salinities $(21 \mathrm{~g} / \mathrm{kg}$ at $1.5 \mathrm{~g} / \mathrm{kg} /$ day, $55 \mathrm{~g} / \mathrm{kg} \mathrm{at} 4 \mathrm{~g} / \mathrm{kg} / \mathrm{day}, 85 \mathrm{~g} / \mathrm{kg}$ at $6 \mathrm{~g} / \mathrm{kg} /$ day, and 105 at $7.5 \mathrm{~g} / \mathrm{kg} /$ day), with an endpoint following 24 hours at the final salinity, and (4) long term acclimation from $\mathrm{FW}$ to $75 \mathrm{~g} / \mathrm{kg}$ at $6 \mathrm{~g} / \mathrm{kg} /$ day followed by maintenance at the final salinity for 10 weeks. Salinity increase in each case was achieved by the addition of a saturated brine solution $(200 \mathrm{~g} / \mathrm{kg})$ made from premixed SW ion blend made for aquariums (Instant Ocean). Brine was added during $10 \%$ total water volume daily water changes to achieve the appropriate salinity increase to within $0.1 \mathrm{~g} / \mathrm{kg}$ as determined using a portable conductivity meter set on salinity mode (TWT Cond 3310 meter, TetraCon 325 probe). At salinities above $60 \mathrm{~g} / \mathrm{kg}, 5 \mathrm{~mL}$ of ammonia/nitrite detoxifier solution (Kordon AmQuel) was added daily to maintain low ammonia and nitrite levels due to reduced biological filtration efficiency. Acclimations 1-3 were conducted in water at $27^{\circ} \mathrm{C} \pm 1^{\circ}$ in $30 \mathrm{~L}$ tanks kept on one three-tiered rack with treatments randomly distributed to avoid biasing results based on increased stress on individuals near walking paths (Speare et al., 1995), differences in light levels, or order of feed distribution. Controls for acclimations 1-3 were transferred to tanks prepared in the same way as experimental tanks and held in FW for 14 days with daily $10 \%$ water change following feeding. Fish were fed once daily ad libitum in the morning three hours after lights-on in the vivarium on a formulated tilapia floating pellet diet $(35 \%$ Hi Production Tilapia Food, Star Milling Company), and the total number of pellets added to each tank was recorded. Following 30 minutes of feeding time with no human interaction, all remaining pellets were retrieved using a dip net and counted. In acclimation 4 , the twelve-week acclimation to $75 \mathrm{~g} / \mathrm{kg}$ salinity, fish were placed in two replicate tanks from each brood population ( $\mathrm{n}=4$ tanks each with $15 \mathrm{fish}$ ) for a total of 60 fish for the $75 \mathrm{~g} / \mathrm{kg}$ treatment and for controls. Because nitrifying bacteria efficiency in biological filters is significantly reduced in salinities above $60 \mathrm{~g} / \mathrm{kg}$ (Cui et al., 2016), alternate tank set-up was needed relative to the other three acclimations. A recirculating system was constructed with $30 \mathrm{~L}$ experimental tanks sitting inside a larger (400L) tank with overflow outlets and a 200L sump containing a flow-through bed of ceramic ring filter media (approx. 15L volume) and protein skimmer (BubbleMagus Curve 7). This allowed for consistent tank size between all acclimations but with a greatly expanded water volume $(600 \mathrm{~L})$ and biological filter capacity (biofilter 
volume of $15 \mathrm{~L}$ versus $0.5 \mathrm{~L}$ per tank) which kept ammonia and nitrite levels below $0.25 \mathrm{ppm}$ without the need for additional detoxifying solution. In this acclimation, feed was weighed before adding to tanks for increased accuracy of measurment. Following the 30-minute undisturbed feeding period, feed was retrieved and placed in labelled plastic bags. Retrieved feed was then oven dried at $105^{\circ} \mathrm{C}$ until weight became constant (approx. 3 hours). Natural pellet dissolution was determined for $10 \mathrm{~g}$ of feed placed in a 30L tank without fish and treated in the same manner and used as a modifier of final pellet weight for each tank. Total feed consumed was calculated by food retrieved multiplied by the dissolution factor and subtracted from feed distributed. by total weight of fish from biweekly weighing and multiplying by 100 to produce determine percentage of body weight consumed daily. Treatment tanks reached the final salinity after two weeks, at which point three fish from each tank were euthanized after visually selecting one large, one median, and one small fish and samples acquired to determine blood osmolality before long term acclimation. To determine weight gain, the remaining 12 fish were removed using a dip net from tanks and placed in a pre-weighed $2 \mathrm{~L}$ pitcher containing water from the tank, final weight recorded, and fish then returned to the tank. This process was repeated every two weeks until the end of the experiment to determine weight change.

\section{Sample collection}

At the time of sample collection, fish were removed one at a time from the tank and quickly euthanized first by manually applied blunt force trauma and then by pithing and exsanguination (Leary et al., 2020). Following pithing, the caudal peduncle was severed and blood was collected in non-heparinized capillary tubes and transferred to a $0.5 \mathrm{~mL}$ centrifuge tube. Tubes were kept at room temperature (RT) for 30 minutes to allow for blood clotting and then centrifuged for 10 minutes at $1000 \mathrm{~g}$. Serum was removed to a labelled $0.5 \mathrm{~mL}$ centrifuge tube and stored at $-80^{\circ} \mathrm{C}$ until further processing. Following blood collection, fish were weighed and total length recorded. Gill arches were removed and soft tissue separated from filament skeleton by scraping with a slide coverslip and placed on a labelled piece of aluminum foil. Gill tissue was snap-frozen in liquid nitrogen and placed in $-80^{\circ} \mathrm{C}$ storage until further processing. Blood serum osmolality measurements were made using undiluted serum when possible, and diluted with pure water (Optima LC/MS Grade, Fisher Chemical) when necessary, with osmolality readings multiplied by the dilution ratio. Osmolality was determined using a freezing-point micro-osmometer (Advanced Instruments model 3300).

\section{Sample processing for proteomics}

Samples from seven treatments were used to compare proteome changes based on time and salinity level, including eight samples each from 14-day acclimations to $85 \mathrm{~g} / \mathrm{kg}$ and $105 \mathrm{~g} / \mathrm{kg}$ as well as the FW control and the 12 -week $75 \mathrm{~g} / \mathrm{kg}$ treatment and FW control, and six samples from the extended constant salinity to $\mathrm{MP}$ at $85 \mathrm{~g} / \mathrm{kg}$ and $105 \mathrm{~g} / \mathrm{kg}$ due to experimental deaths of two fish in each treatment. Extraction and in-solution trypsin digestion of proteins were performed as previously reported (Root et al., 2021a). Peptide samples $(2 \mu \mathrm{l}, 100 \mathrm{ng} / \mu \mathrm{l})$ were injected with a nanoAcquity sample manager, trapped for $1 \mathrm{~min}$ at 15 $\mu \mathrm{L} / \mathrm{min}$ on a Symmetry trap column, and separated on a $1.7 \mu \mathrm{m}$ particle size BEH C18 column by reversed phase liquid chromatography using a nanoAcquity binary solvent manager. Peptides were eluted using a 125 min linear gradient ranging from $3 \%$ to $35 \%$ acetonitrile (ACN) directly (online) into a UHR-qTOF mass spectrometer using a pico-emitter tip. Batch processing of samples was controlled with Hystar 4.1 and a 68 fmol BSA peptide mix quality control standard was used intermittently between samples to monitor instrument performance.

\section{Data Dependent Acquisition proteomics}

Peak lists were generated from DDA raw data with DataAnalysis 4.4 (Bruker Daltonics) and peptide to spectrum matches identified with PEAKS suite X plus (Bioinformatics Solutions Inc., Waterloo, Canada) and X!Tandem Alanine (The GPM) database search engines followed by unambiguous assignment of peptides to unique proteins using the O. niloticus proteome database downloaded from NCBI RefSeq on Feb. 25, 2020 , supplemented with known O. mossambicus protein sequences. The search database included 61,681 proteins and an equal number of randomly scrambled decoys along with 282 common contaminants (human keratins, porcine trypsin, etc.). Trypsin cleavage was specified at the C-terminus of Lysine or Arginine except when 
followed by Proline, and a maximum of two missed cleavages were allowed. Possible PTMs were searched by allowing for Cysteine carbamidomethylation, Methionine oxidation, and Protein N-terminal acetylation. Additionally, second-round searches considered all 313 PEAKSPTM modifications included in the default PEAKS suite X plus database, allowing max. 3 PTMs per peptide. Mass tolerance limits were set at 10 ppm for precursors and $0.03 \mathrm{Da}$ for fragment ions. All DDA data and metadata are available at MassIVE (MSV000085745) and ProteomeXchange (PXD020364).

\section{Raw spectral library and DIA assay library construction}

An O. mossambicus gill spectral library was generated using the peptide-to-spectrum matches and protein annotations from DDA data. Data was exported from PEAKS suite X plus in mzxml and pepxml formats and imported into Skyline 4.0 (Pino et al., 2017) to create a non-redundant raw library of MS2 spectra. The initial target list of proteins was filtered using multiple QC criteria to reduce the number of transitions, precursors, peptides, and proteins to a unique set which provided the highest diagnostic value for quantitation. Transitions for the initial target list were chosen automatically from library spectra using Skyline transition settings based on the following criteria: ion 3 to last ion -1; fragment ion charge 1; precursor charge range 1 5; MSMS mass accuracy threshold within $20 \mathrm{ppm}$ of the expected mass. This initial target list was filtered in seven sequential steps using Skyline following a previously published method (Li et al., 2018). Briefly, steps included (1) requiring at least 2 peptides per protein and 4 transitions per precursor, (2) eliminating peptides with more than 1 missed cleavage, (3) excluding uncommon PTMs, (4) creating a training set consisting of all 12 samples, after first subjecting them to iRT calibration and mProphet peak detection using Skyline, and then further refining the target list by exclusion of all peptides with dotp values lower than 0.8, (5) enforcing peptide uniqueness by protein and eliminating iRT outliers, (6) removing peptides which were not unique to a single protein, and (7) limiting to 10 the maximum number of peptides per protein. The final filter steps utilized a sample training set, which was acquired by DIA as described in the next paragraph. The complete assay library including all relevant metadata and corresponding data for the sample training set is available at Panorama Public (https://panoramaweb.org/lr03.url). This assay represents a tier two assay (Abbatiello et al., 2017).

\section{Data Independent Acquisition (DIA)}

Each sample was analyzed by a second acquisition run using data independent (DIA) mode. LC separation parameters and conditions were identical to those used for DDA but only MS2 were acquired. The DIA mass range was set to $390-1015 \mathrm{~m} / \mathrm{z}$ at $25 \mathrm{~Hz}$ scan rate with an isolation width of $10 \mathrm{~m} / \mathrm{z}(1 \mathrm{~m} / \mathrm{z}$ overlap, $2.5 \mathrm{sec}$ scan interval). Quantitative analyses and visualization of DIA data was performed using Skyline 20.0 (Pino et al., 2017). At least four (generally six) transition peaks were detected for each peptide and scored using the integrated Skyline algorithm mProphet. The mass error threshold was set to $20 \mathrm{ppm}$ for transitions, and resolving power was 30,000. Randomly scrambled decoys were used in mProphet Q-value calculation. MSstats 3.1 (Choi et al., 2014) was used for power analysis to calculate the fold-change (FC) cutoff that was appropriate for each experiment, as well as statistical significance of differences between treatment and control. The cutoff for multiple testing adjusted p-values (Benjamini \& Hochberg, 1995) was set to $\mathrm{p}<0.05$. MSstats analyses were normalized by equalizing medians at a minimum confidence interval of $95 \%$ using protein quantity as the scope for the analysis. Tukey's median polish was used as the summary method for MSstats analyses to weight each transition and each peptide of a given protein equally. The minimal mProphet detection Q-value for peak quality was set to 0.01. All DIA data can be accessed at PanoramaPublic (https://panoramaweb.org/lr03.url) and ProteomeXchange (PXD029254).

\section{STRING analysis}

Protein-protein interaction networks were produced using STRING ver. 11.0 (Szklarczyk et al., 2019) (https://string-db.org/) for important groups of significant proteins, including those significantly regulated in all treatments. Lists of accession numbers for these significant proteins were entered in the search function "multiple proteins", creating network maps with line connections based on scientific literature. Enrichment values were determined as over-representation of list members with high or low FC in STRING functional 
clusters, Uniprot keywords, and Pfam, InterPro, or SMART protein domains with a false discovery rate $($ FDR $)<0.05$ after correcting for multiple testing using the Benjamini-Hochberg procedure.

\section{Correlation analysis}

The ratio of blood osmolality, body condition, time at high salinity $(>65 \mathrm{~g} / \mathrm{kg})$ and salinity at time of sample collection versus the control value for each treatment used in the proteomic analysis was compared against the FC for this treatment was used to compare treatments based on linear correlation coefficient $\left(\mathrm{r}^{2}\right)$. To account for differences between the short-term and long-term acclimation controls due to the high feed rate and age difference between these two, the controls were compared using the same procedure as each treatment to control with MSstats 3.1 and any proteins which were significantly different between controls were not considered. Following this filtering step, proteins with $\mathrm{r}^{2}$ greater than 0.9 were identified and further refined to only those proteins which were significantly regulated in at least one treatment. To determine functional groups which were most correlated with a given parameter, the list of accession numbers of proteins which met the above conditions were searched on the STRING database and networks identified.

Results:

\section{Salinity Tolerance}

Non-lethal endpoints indicative of a fish approaching a moribund state are necessary to avoid unnecessary physical distress to animals and for the collection of useable tissue samples. Aberrant swimming and movements are an indicator of this approaching state, and it was initially assumed based on previous experiments determining the maximum critical salinity $\left(\mathrm{CS}_{\mathrm{MAX}}\right)$ that the appropriate endpoint was the inability to maintain upright position, or loss of equilibrium (LOE). Preliminary experiments conducted with six individuals acclimated using a continuous increase of $6 \mathrm{~g} / \mathrm{kg}$ indicated that this behavior did not precede more severe impacts including pronounced lethargy and cessation of feeding, and that a different endpoint was necessary. Fish approaching a moribund state exhibited several behaviors including: constant fin movement, inability to maintain position in the water column, sustained darkened coloration, and highly reduced feeding. Unfortunately, none of these were consistently observed in all fish. The most consistent behavior was found to be non-reactivity to a potential threat, specifically a dip-net. Normally functioning fish will evade capture in a net, and though fish appear to move less frequently under salinity stress, they still will approach food pellets and avoid nets. When a fish no longer evades the net, this appears to be the most consistent response and indicator that they will become moribund before the following monitoring timepoint, and for this reason we have used the term "morbidity point" (MP). This behavioral response is presented as an alternative endpoint when other responses such as LOE are not applicable.

Two fish in the preliminary experiments which had reached MP were rescued by reducing salinity, suggesting that this state not terminal if the salinity stress is ameliorated. In trials with an MP endpoint, constant fish monitoring allowed for capture of fish before death in most cases as this was necessary for acquiring usable serum and tissues for proteomics. Nonetheless, some individuals were found dead and MP estimated to the closest hour since the previous monitoring timepoint for determining maximum salinity tolerance. Experimental mortalities were not used for proteomic analysis. No premature deaths were recorded in the 14-day acclimation trials to target salinity.

In experiments with continuous gradual salinity increase at variable rates, the mean salinity at MP were as follows: $32.0 \mathrm{~g} / \mathrm{kg}$ at $32 \mathrm{~g} / \mathrm{kg} /$ day, $69.0 \mathrm{~g} / \mathrm{kg}$ at $24 \mathrm{~g} / \mathrm{kg} /$ day, $106.8 \mathrm{~g} / \mathrm{kg}$ at $12 \mathrm{~g} / \mathrm{kg} /$ day, $117.0 \mathrm{~g} / \mathrm{kg}$ at $8 \mathrm{~g} / \mathrm{kg} / \mathrm{day}$, and $114.6 \mathrm{~g} / \mathrm{kg}$ at $6 \mathrm{~g} / \mathrm{kg} /$ day (Figure $1 \mathrm{~A}$ ). Rate of salinity increase was clearly important in determining $\mathrm{CS}_{\text {MAX }}$, but lower rates avoid acute affects and resulted in relatively consistent $\mathrm{CS}_{\text {MAX }}$. Finding the mean of the $\mathrm{CS}_{\text {MAX }}$ for the $8 \mathrm{~g} / \mathrm{kg} /$ day and $6 \mathrm{~g} / \mathrm{kg} /$ day rates indicates an acclimatory CS $_{\text {MAX }}$ of approximately $115 \mathrm{~g} / \mathrm{kg}$ for this population and experimental set-up. This result is not meant to represent the $\mathrm{CS}_{\mathrm{MAx}}$ for the species generally, but rather to define the pessimum salinity range for this population so that appropriate samples representative of stages of upper range salinity tolerance could be chosen for later proteomic analysis. For extended exposure to constant salinity experiments, decreasing increments of $10 \mathrm{~g} / \mathrm{kg}$ lower than the $\mathrm{CS}_{\text {MAX }}(115 \mathrm{~g} / \mathrm{kg})$ were used until a salinity was found in which fish were able to survive indefinitely to 
determine the critical salinity threshold. The mean times until MP at these salinity levels were as follows: 263 hours at $105 \mathrm{~g} / \mathrm{kg}, 326$ hours at $95 \mathrm{~g} / \mathrm{kg}$, and 559 hours at $85 \mathrm{~g} / \mathrm{kg}$ (Figure $1 \mathrm{~B}$ ). At $75 \mathrm{~g} / \mathrm{kg}, 79 \%$ of individuals survived for 10 weeks, which was the endpoint the experiment.

\section{Whole organism physiology}

\section{Blood osmolality}

Blood osmolality values were collected for all treatments in the 14-day acclimations and treatments at extended constant salinity (Figure 1C). Blood osmolality was significantly higher $(\mathrm{p}<0.05)$ for all treatments compared with control except $21 \mathrm{~g} / \mathrm{kg}$. Blood osmolality was $810 \mathrm{mOsm} \pm 92.6$ at MP for the $85 \mathrm{~g} / \mathrm{kg}$ treatment and $797 \mathrm{mOsm} \pm 107.7$ at $\mathrm{MP}$ for the $105 \mathrm{~g} / \mathrm{kg}$ treatment. Both treatments had significantly higher $(\mathrm{p}<0.05)$ blood osmolality versus 14 -day and 12 -week FW handling controls. Blood osmolality was $389 \mathrm{mOsm} \pm 19.1$ following 10 weeks at $75 \mathrm{~g} / \mathrm{kg}$, and $353.9 \mathrm{mOsm} \pm 6.38$ for the handling control. Following 24 hours after acclimation to $75 \mathrm{~g} / \mathrm{kg}$ in this experiment, blood osmolality was $399 \pm 19.2$. Acute salinity stress following transfer to $32 \mathrm{~g} / \mathrm{kg}$ had a mean blood osmolality of 655 mOsm \pm 20.8 at MP $(\mathrm{n}=8)$.

\section{Body condition}

Fulton's body condition factor $(\mathrm{K})$ was calculated for fish following the 14-day acclimation and the extended constant salinity treatments (Figure 1D). K was significantly lower $(2.79$ vs. $3.12, \mathrm{p}=0.013)$ for the $105 \mathrm{~g} / \mathrm{kg}$ treatment compared with handling controls. For extended constant salinity to MP, K was $2.67 \pm 0.173$ for the $85 \mathrm{~g} / \mathrm{kg}$ treatment and $2.53 \pm 0.415$ for the $105 \mathrm{~g} / \mathrm{kg}$ treatment, both of which were significantly lower $(\mathrm{p}<0.05)$ versus 14 -day and 12 -week FW handling controls. Following 10 weeks at $75 \mathrm{~g} / \mathrm{kg}, \mathrm{K}$ was $2.98 \pm$ $0.264, \mathrm{~K}$ for handling controls was $3.05 \pm 0.242$, and $\mathrm{K}$ following 24 -hours at $75 \mathrm{~g} / \mathrm{kg}$ was $3.16 \pm 0.376$.

\section{Feeding}

In the 14-day acclimation, fish at $21 \mathrm{~g} / \mathrm{kg}$ appeared to increase feeding compared to the control, although this trend was not significant by the conclusion of the experiment (Figure 1E). The $55 \mathrm{~g} / \mathrm{kg}$ treatment feeding behavior was very similar to the control. Both the $85 \mathrm{~g} / \mathrm{kg}$ and $105 \mathrm{~g} / \mathrm{kg}$ treatments decreased towards complete cessation of feeding as the target salinity was reached. For extended constant salinity at $85 \mathrm{~g} / \mathrm{kg}$, feeding dropped to near zero over the 14-day acclimation period before rising slightly and finally falling back towards zero as fish reached MP. At $105 \mathrm{~g} / \mathrm{kg}$ constant salinity feeding dropped to near zero during acclimation and remained near zero until MP. At $75 \mathrm{~g} / \mathrm{kg}$, feeding dropped to near zero during the acclimation period but recovered to near the feeding rate of the handling control, although at 12-weeks feeding was still significantly lower $(\mathrm{p}=0.0093)$ than the control (Figure 2C).

\section{Growth}

Growth was measured biweekly for the $75 \mathrm{~g} / \mathrm{kg}$ extended salinity experiment (Figure 2B). Control and treatment diverged significantly in weight after two weeks at $75 \mathrm{~g} / \mathrm{kg}$ (week 4 weighing). By the end of the experiment, weight was not significantly greater in the $75 \mathrm{~g} / \mathrm{kg}$ treatment versus the end of acclimation (week 2 time point). Overall, mean weight increased by $37 \%$ from the original weight in the $75 \mathrm{~g} / \mathrm{kg}$ treatment over 12 weeks from $3.756 \mathrm{~g} /$ fish to $5.173 \mathrm{~g} /$ fish. In comparison, the control treatment increased by $214 \%$ of the original weight from $3.933 \mathrm{~g} /$ fish to $12.37 \mathrm{~g} / \mathrm{fish}$.

\section{DIA quantitative proteomics}

\section{Construction of the DIA assay library}

The raw MS2 spectral library from data-dependent acquisition (DDA) LCMS2 data of all samples contained 16,306 proteins, 139,790 peptides, 154,426 precursors (different charge states of peptides), and 864,374 transitions (fragment ions) (Supplementary fig. 1. Applying the quality control (QC) filter steps resulted in a final DIA assay library comprised of a target list containing 68,586 transitions, 13,847 precursors (one per peptide), and 3024 proteins. Despite requiring each protein to be represented by at least two unique peptides in the raw spectral library, $27.3 \%$ (825) of the proteins are only represented by a single peptide (although 
multiple transitions) in the final DIA assay library because other peptides were excluded during DIA assay library construction if they did not meet the QC criteria in all filter steps.

\section{Proteome regulation during salinity stress}

Proteomic analysis was performed for seven treatments using the same DIA assay library. The mass error threshold was $<20 \mathrm{ppm}$ for all transitions in all samples and $<10 \mathrm{ppm}$ for the great majority, and retention time reproducibility of the data was very high as well (Supplementary fig. 2). A fold-change (FC) threshold of 2.0 was enforced for all treatments in considering statistical significance based on the coefficient of variation calculated with MSstats (Choi et al., 2014), providing at least 0.8 statistical power for p-values $>0.05$. Furthermore, the majority of transition peaks for all samples in this dataset had mProphet (Reiter et al., 2011) peak scores of $\mathrm{q}<0.01$, the peak quality threshold for inclusion in MSstats quantitative DIA data analysis.

Acclimation to $85 \mathrm{~g} / \mathrm{kg}$ resulted in 234 significantly upregulated and 171 significantly downregulated out of 2971 total proteins quantified, while acclimation to $105 \mathrm{~g} / \mathrm{kg}$ yielded 348 significantly upregulated and 255 significantly downregulated out of 2972 total proteins quantified (Figure 3A, Supplementary table 1). Extended exposure resulted in 501 significantly upregulated and 481 significantly downregulated out of 3015 proteins quantified at MP in $85 \mathrm{~g} / \mathrm{kg}, 486$ significantly upregulated and 473 significantly downregulated out of 3015 proteins quantified at MP in $105 \mathrm{~g} / \mathrm{kg}$, and 311 significantly upregulated and 149 significantly downregulated out of 3011 proteins quantified after ten weeks at $75 \mathrm{~g} / \mathrm{kg}$.

The ten most highly upregulated and downregulated significant proteins based on FC were determined for each treatment and compared between treatments (Figure 3B). The most highly upregulated protein in all extended constant salinity treatments and the second most highly upregulated in the 14-day acclimations was inositol monophosphatase 1 isoform X1 (IMPase1-X1), which had a maximum upregulation in the extended $85 \mathrm{~g} / \mathrm{kg}$ salinity treatment of $438 \mathrm{FC}$ and an average FC increase of 225 across all five treatments. Solute carrier family 12 member 2 isoform X1 (SLC12a2-X1) was the highest upregulated protein in both 14-day acclimations and the second most highly upregulated protein in the extended treatments, with an average of 90 times greater across all treatments. The most highly downregulated protein in four of the five treatments was an uncharacterized protein, LOC100699110 isoform X1, which was 1137 times lower in the extended $105 \mathrm{~g} / \mathrm{kg}$ exposure and 513 times lower on average across all treatments.

There was a large degree of overlap in significantly regulated proteins in each treatment (Figure 3C). The greatest number of shared proteins was between samples taken at MP, with 472 of the significantly regulated proteins shared between the extended exposure at $85 \mathrm{~g} / \mathrm{kg}$ and at $105 \mathrm{~g} / \mathrm{kg}$. The second largest group of overlapping proteins were those which were significantly regulated in all treatments, including 161 proteins. The extended salinity treatments each had many proteins which were only significantly regulated in one treatment, with 144 uniquely significant proteins in the $85 \mathrm{~g} / \mathrm{kg}$ salinity, 110 in the $105 \mathrm{~g} / \mathrm{kg}$ salinity, and 87 in the $75 \mathrm{~g} / \mathrm{kg}$ salinity. A total of 78 proteins were significantly regulated in all four treatments which were above the critical salinity threshold.

\section{Network analysis \\ STRING network for significant proteins in all treatments}

A protein network map was created visually representing the response of $O$. mossambicus gill proteins to hypersaline conditions regardless of time of exposure or position relative to the critical threshold using all 161 proteins significantly regulated in all treatments. The majority (122) of accession numbers matched to STRING IDs, and 86 were connected to at least one other protein. The network map of all connected proteins contains many proteins involved in the electron transport chain (ETC), with 36 of the 86 total proteins being a subunit of one of the five ETC complexes (Figure 4). Core members of the glycolysis and tricarboxcylic acid (TCA) cycle pathways accounted for another 17 nodes of this network map. Only three of the proteins in the network map were downregulated, $\mathrm{Na}^{+} / \mathrm{K}^{+}$-ATPase $\alpha-1$ isoform X4, Alkylglycerone phosphate synthase, and $\mathrm{NH}_{4}{ }^{+}$transporter Rh-B. One of the clusters which is highly connected included 
two isoforms of acetyl-CoA acyltransferase, two isoforms of aldehyde dehydrogenase 6-A1, two trifunctional proteins, enoyl-CoA $\delta$ isomerase 1 , and electron transfer flavoprotein $\beta$. Another important set of nodes on this map are the two isoforms of IMPase, one of which was the most highly upregulated protein in many treatments.

\section{STRING networks for pejus and pessimus range physiological states}

All treatments $85 \mathrm{~g} / \mathrm{kg}$ and greater represent pessimum range salinities given the ultimate MP endpoint at this salinity. Network analysis was run for the 78 proteins shared by 14-day acclimations and extended salinity treatments at $85 \mathrm{~g} / \mathrm{kg}$ and $105 \mathrm{~g} / \mathrm{kg}$ and compared with the networks for the 87 proteins unique to the extended $75 \mathrm{~g} / \mathrm{kg}$ treatment. Networks were identified with greater than three nodes and classified using ontological term enrichment. Pejus range regulation consisted of a network of mostly upregulated proteins with enrichment in amino acid metabolism and oxidoreductase terms including lactate dehydrogenase (LDH) and glycogen synthase, a network of mixed up and down-regulation of structural proteins, especially myosin subunits, and downregulation of proteasome proteins (Figure 5A). Pessimum range networks contained specific upregulated mitochondrial proteins, with subunits in the cytochrome b-c1 complex as central members, and downregulation of extracellular matrix proteins (ECM) with several collagen subunits (Figure 5B).

\section{Correlations of protein networks with physiological parameters}

Correlation coefficient was determined between organismal measurements versus protein FC. Correlated variables included blood osmolality, condition factor (K), experimental salinity, and time at salinity above $65 \mathrm{~g} / \mathrm{kg}(\sim 2 \mathrm{X} \mathrm{SW})$. Of these variables, blood osmolality difference from treatment to control was correlated with protein abundance with $\mathrm{r}^{2}>0.9$ for 446 proteins, with 280 of these proteins being significantly regulated in at least one treatment (Supplementary Table 2). Condition factor difference was correlated with $\mathrm{r}^{2}>0.9$ for 212 proteins, of which 125 were significantly regulated in at least one treatment. Experimental salinity was correlated with an $\mathrm{r}^{2}>0.9$ for only 16 proteins ( 6 significant) and time above $65 \mathrm{~g} / \mathrm{kg}$ was correlated with an $\mathrm{r}^{2}>0.9$ for 51 proteins (20 sig). Proteins with high blood osmolality correlation were analyzed using the STRING database, revealing one network with greater than three nodes which consisted of proteins involved in cell adhesion, ECM organization, and junctional complexes (Figure 5C). The STRING database annotated six of these proteins as associated with the serpin protein domain (SERine Protease Inhibitor), including serine protease inhibitor A3K, $\alpha$-1-antitrypsin, protein Z-dependent protease inhibitor, angiotensinogen, complement factor D, and heparin cofactor 2. Four of the proteins were found in the "focal adhesion" KEGG molecular pathway, including $\alpha$-actinin-1 X3, fibronectin, and two integrins ( $\alpha-1$ and $\alpha-6$ X1). All proteins had negative slopes (decreasing FC with increasing blood osmolality) except for catenin $\delta-1$ X3 and tropomyosin $\beta \mathrm{X} 2$, and the later was also found in a pejus range network.

\section{Identifying Uncharacterized Protein LOC100699110 - X1}

The most highly regulated protein analyzed was an uncharacterized protein given the NCBI accession number XP_019220227.1. Searching the amino acid sequence using the NBCI pBLAST found the closest annotated proteins to be fucolectin, pentraxin fusion-like protein, and tenascin (Supplementary fig. 3). Examining the amino acid sequence revealed that protein XP_019220227.1 consists mainly of eleven repeats of 143 amino acids with $94.4 \%$ identity between repeats. Searching the repeat sequence on pBLAST returned matches with high identity to fucolectins from different teleost fish with E-values lower than 2E-70 and identity greater than 75\%. Matching fucolectins were much shorter, between 147 and 321 amino acids long in comparison with the 1605 amino acid length of the uncharacterized protein.

\section{DISCUSSION}

\section{Salinity tolerance}

Physiological tolerance limit of fish species to environmental stressors is species-specific and sensitive to time course of exposure. Common assessments of upper salinity limits such as LOE may not be applicable to 
all species (Schultz \& McCormick, 2012), and in this experiment the use of an endpoint which involved non-reactivity to a dip-net, a threat which all normally functioning fish recognized, was used to determine approaching morbidity. Several fish in this state were rescued through transfer to improved conditions, suggesting that they were still functional with physiological and molecular phenotypes representative of living individuals, not post-mortem internal processes. The term Morbidity Point (MP) was used to describe this endpoint.

An exposure protocol was developed to account for salinity level, time of exposure, and salinity rate of change. Salinity tolerance is often assessed in a binary fashion between acute exposure i.e. direct transfer from initial to final salinity, and chronic exposure which involves gradual salinity change to the endpoint (Schultz \& McCormick, 2012). These assessments do not fully capture the dynamics of salinity acclimation, as a high rate of salinity change may outpace the necessary alterations in phenotype required for acclimation. Additionally, without duration at a final salinity one cannot assess the breadth of the zone of resistance (pessimum range). Previous assumptions about survival for a specific amount of time representing long term-survivability may be inaccurate, as $O$. mossambicus can survive in salinity above the incipient lethal salinity for up to six weeks.

O. mossambicus has been recorded in nature in salinities up to $120 \mathrm{~g} / \mathrm{kg}$, with historical data indicating that they can remain in extreme hypersaline conditions for weeks and even months (Whitfield et al., 2006). This data aligns with our results, with fish able to survive for several weeks above $100 \mathrm{~g} / \mathrm{kg}$, and for months at levels near $75 \mathrm{~g} / \mathrm{kg}$. Experimental conditions are of course different from natural conditions, and impacts of predator avoidance and searching for food can increase the effects of environmental stress (Davis et al., 2019). Nevertheless, extreme hypersaline ecosystems have greatly reduced species diversity and thus $O$. mossambicus is likely to experience fewer predators and greater food availability due to fewer competitors (Whitfield et al., 2006).

\section{Salinity exposure near Critical Threshold eliminates growth}

Energy homeostasis theory places survival as the final biological capacity lost when animals are exposed to pessimum range stressors for too long (Sokolova et al., 2012). Fish can sustain life in pejus range stress levels, but energy demands required for survival, sub-optimal enzymatic function, and/or contending with deleterious effects of increased metabolic processes contribute to reduced growth or reproduction, ultimately reducing the functional capacity of individuals and populations. This was demonstrated clearly through the 12-week exposure to $75 \mathrm{~g} / \mathrm{kg}$ treatment experiment, where most fish were able to survive and maintain blood osmolality, body condition, and feeding rate close to control levels, but growth was dramatically reduced to the point of no significant weight increase.

Absolute salinity and time of exposure each played a role in determining the internal level of stress, i.e. distortion from homeostasis. Physiological parameters such as blood osmolality and body condition were significantly impacted by extreme hypersalinity with greater change from controls at higher absolute salinity. However, over time the difference between fish held at $85 \mathrm{~g} / \mathrm{kg}$ and $105 \mathrm{~g} / \mathrm{kg}$ was erased when MP was reached, whereas internal levels were maintained at $75 \mathrm{~g} / \mathrm{kg}$, indicating a clear external salinity threshold based on ultimate outcome. Internal blood osmolality was also higher in fish held at $85 \mathrm{~g} / \mathrm{kg}$ or $105 \mathrm{~g} / \mathrm{kg}$ at MP versus acute exposure to $32 \mathrm{~g} / \mathrm{kg}$ at MP, pointing to a greater acclimatory upper limit of blood osmolality in chronic exposures versus acute salinity change. Protein abundance changes were most highly correlated with blood osmolality, providing evidence that gill molecular phenotypes are not a direct result of specific salinity levels or exposure times, but rather that specific combinations of salinity, time of exposure, and rate of increase lead to different internal states and survival outcomes.

\section{Protein Networks}

\section{Regulation in hypersalinity}

The largest and most highly connected cluster in the network of significantly regulated proteins in all treatments included mitochondrial proteins involved in the ETC. Multiple previous proteomic studies with Ore- 
ochromis species have shown the widespread upregulation of mitochondrial proteins during acclimation to higher salinity levels, especially as these levels approach the upper range of species specific salinity tolerance (Kültz et al., 2013; Root et al., 2021a, 2021b). Microscopy has shown that ionocytes, the main site of transepithelial ion transport in fish gills (Evans et al., 2005), increase in number within 12 hours and the total number of ionocytes remains elevated following transfer of $O$. mossambicus from FW to SW (Hiroi et al., 2005). Additionally, SW-specific ionocyte subtypes are significantly larger than ionocytes from fish in FW (Kültz et al., 1995). Ionocytes, once called mitochondrial rich cells (MRCs) (Inokuchi et al., 2009), are characterized by high concentrations of mitochondria, which is reflected in protein abundance patterns from this and previous studies.

In addition to ETC proteins, the generalized hypersalinity response network has a strong representation of glycolysis and the TCA cycle proteins, emphasizing the importance of increased energy production in response to hypersaline conditions in initial and long-term stages of exposure. These proteomic responses combined with decreasing body condition/growth indicate that one of the dominant adaptive mechanisms of O. mossambicus to hypersaline conditions is to increase energy production and allocation to meet increased osmoregulatory energy requirements. Osmoregulation can account for 20-50\% of basal metabolic cost across a range of taxa in fish (Bœuf \& Payan, 2001). Comparing O. mossambicus oxygen consumption rates, which is linked to metabolic rate, fish acclimated to SW consumed less oxygen than in FW, but fish acclimated to hypersaline water at 1.6X SW salinity had higher oxygen consumption than in FW or SW (Iwama et al., 1997). Evidence is scant for salinity levels as high as those used in this study, but it is reasonable to suggest that increasing hypersalinity requires greater energy production, especially given that much of the active ion transport is ATP-dependent.

Proteins directly related to ion regulation in the network of significant proteins in all treatments, specifically ion transporters $\left(\mathrm{Na}^{+} / \mathrm{K}^{+}\right.$ATPase, $\mathrm{NH}_{4}{ }^{+}$transporter) and compatible osmolyte synthesis enzymes (IMPase, sorbitol dehydrogenase), are present but are peripheral in the network map and do not contain many members. Small numbers of significant proteins combined with a high degree of regulation (many are among the most highly regulated proteins), indicate that the ion balance is controlled through highly targeted regulation of specific proteins and subunits. This contrasts with the regulation of energy production, which is comprehensive and involves a large network cluster. Targeted regulation of ion transport includes isoform switching in $\mathrm{Na}^{+} / \mathrm{K}^{+}$ATPase subunits, as the $\alpha-1$ isoform X1 increased by an average of 10 -fold greater in all treatments while $\alpha-1$ isoform X4 decreased by 20 -fold on average. Isoform switching in $\mathrm{Na}^{+} / \mathrm{K}^{+} \mathrm{ATPase}$ subunit $\alpha$ has been documented in O. mossambicus (Tipsmark et al., 2011) and other fish species (Richards et al., 2003) during salinity acclimation. IMPase 1 isoform X1 was the most highly upregulated protein on average across treatments, which is consistent with previous proteomic analyses. InO. mossambicus, myo -inositol is synthesized to counteract increased intracellular electrolyte concentration through a twostep metabolic path from D-glucose by the enzymesmyo -inositol-3-phosphate synthase (MIPS) and IMPase (Gardell et al., 2013). MIPS was also significantly upregulated in all treatments except the extended $75 \mathrm{~g} / \mathrm{kg}$ exposure. Myo -inositol concentration is also regulated in $O$. niloticus kidney during salinity acclimation, although here the mechanism is to reduce degradation by downregulating myo-inositol oxidase(Root et al., 2021b). Interestingly, no myo -inositol related proteins were significantly regulated by salinity in gills of $O$. niloticus, which has an upper salinity tolerance limit near $25 \mathrm{~g} / \mathrm{kg}$ (Root et al., 2021a).

A novel cluster is found in the lower portion of the generalized salinity response network connected to the TCA cycle and ETC clusters which includes proteins involved in fatty acid $\beta$-oxidation and detoxification. AcetylCoA acyltransferase is involved in producing acetyl-CoA through $\beta$-oxidation to be processed in the TCA cycle. Aldehyde dehydrogenase (ALDH) is involved in fatty acid metabolism but also neutralizes carbonyl compounds resulting from lipid peroxidation (Laskar \& Younus, 2019). Increased oxidative phosphorylation and other metabolic processes create harmful molecules such as reactive oxygen species (ROS) and carbonyl compounds (Bazil et al., 2016). Lipid peroxidation is one result of oxidative stress causing turnover in lipid membranes and the formation of toxic fatty aldehydes. ALDH plays a large role in converting these fatty aldehydes into fatty acids (Zeng et al., 2021), and was also highly upregulated in O. niloticus kidney indicating that this response is conserved across species and tissues (Root et al., 2021b). Upregulation of 
acetyl-CoA acyltransferase has also been observed in other organisms exposed to toxic compounds such as in mice exposed to perflourooctane sulfonate (Rosen et al., 2010), diphenylarsinic acid (Yamaguchi et al., 2019), and in bacterial communities exposed to hydrocarbon spills in nature (Edet \& Antai, 2018).

\section{Pejus range protein network regulation}

Stress level specific responses fall into two broad categories; upregulation in energy metabolism and variable regulation of structural proteins. Pejus range regulation networks include one with mostly upregulated proteins, many of which participate in amino acid metabolism. Downregulation of the proteasome affects both energy and amino acid metabolism. It reduces protein turnover to redirect energy towards osmoregulation and it may reduce the availability of free amino acids liberated from degraded proteins. As noted earlier, specific markers for passing the critical threshold into the pessimum range during thermal stress may not apply during salinity stress. Thermal stress is predicted to lead to increased lactate through anaerobic metabolism only above the critical threshold (Sokolova et al., 2012), whereas our data show upregulation in LDH only occurs in the $75 \mathrm{~g} / \mathrm{kg}$ treatment. Energy demand required in hypersalinity appears to be supplied mainly through oxidative phosphorylation and carbohydrate metabolism with some additional fatty acid $\beta$-oxidation. In addition, in the Pejus range, amino acid metabolism is significantly affected, which may contribute to the regulation of energy metabolism (e.g. via regulation of gluconeogenesis).

The other major protein network includes structural proteins such as several myosin subunits which are significantly upregulated in pejus range salinities but significantly downregulated in pessimum range salinities. However, tropomyosin $\beta$ is significantly downregulated in the pejus range and upregulated (n.s.) in the pessimum range, and is one of the proteins most highly correlated with blood osmolality. The regulation of structural proteins is further discussed in the following section.

\section{Pessimum range protein network regulation}

The energy metabolism protein network associated with the pessimum range consists mainly of mitochondrial proteins. Two of these, cytochrome b-c1 complex subunits 7 and Reiske, where also found to be strongly correlated with blood osmolality, indicating that these proteins may be rate-limiting or particularly sensitive to salinity. Cytochrome b-c1 complex subunit 7 was the most highly upregulated mitochondrial protein and ATP/ADP translocase was also significantly upregulated in $O$. niloticus gill near the upper salinity tolerance for this species $(25 \mathrm{~g} / \mathrm{kg}$ ) (Root et al., 2021a). This observation may indicate that $25 \mathrm{~g} / \mathrm{kg}$ already represents the pessimum range for the strain of $O$. niloticus used in this previous study.

Structural changes in the pessimum range include downregulation of ECM proteins including collagen subunits, and proteins forming the connection between the ECM and cell membrane, e.g., integrin- $\alpha$. Most of the proteins whose abundances were highly correlated with blood osmolality were significantly regulated following extended time in the pessimum range, and these proteins were all involved in determining cellular structure. Within this network of highly correlated proteins is a group of Serpins, as well as multiple proteins involved in focal adhesion connections between the cell membrane and ECM. Serine proteases were the most highly downregulated ontological category in gills of $O$. niloticus acclimated to high salinity (Root et al., 2021a), whereas in the present study serine protease inhibitors were downregulated. Clearly serine protease action is important for osmotic regulation of gill protein networks. These proteins are connected by STRING networks to structural and ECM proteins, and they are highly responsive to the intensity of salinity stress rather than being uniformly regulated during hypersaline exposure. Structural proteins were a functional category with a high degree of non-linearity in regulation of mRNA and proteins in O. niloticus, further indicating that cell structure regulation is complex and likely fluctuates in response to internal and external signaling, especially around the critical threshold.

Changes in ionocyte numbers and composition in the gill epithelium lead to changes in overall structure of the tissue. O. mossambicus has dramatically reduced epithelial permeability as salinities increase above SW (Kültz \& Onken, 1993). Ionocytes involved in osmoregulation in high salinity environments have unique "deep-hole" apical crypts in comparison with other types of ionocytes (Fridman et al., 2013; Lee et al., 2000). In high salinity, ionocytes form cell specific clusters (Inokuchi \& Kaneko, 2012), and the gill epithelium deve- 
lops a complex microtubule network along the basolateral membrane layer (Karnaky, 1986). The formation of tubulin networks in response to salinity was first noted decades ago in Cyprinodon variegatus andFundulous heteroclitus (Karnaky, 1986; Karnaky et al., 1976). Although they were not found in the STRING network, tubulin $\alpha-1 \mathrm{~A}$ and $\alpha-1 \mathrm{~B}$ chain both decreased in a highly correlated way with increasing blood osmolality (significantly downregulation of both in extended $105 \mathrm{~g} / \mathrm{kg}$ treatment, and of $\alpha-1 \mathrm{~A}$ for extended $85 \mathrm{~g} / \mathrm{kg}$ ). On the other hand, tubulin $\alpha-1 \mathrm{C}$ chain and tubulin $\beta$ were both significantly upregulated in $85 \mathrm{~g} / \mathrm{kg}$ and $105 \mathrm{~g} / \mathrm{kg}$ treatments at MP and significantly downregulated in the $75 \mathrm{~g} / \mathrm{kg}$ treatment. This is interesting in itself, but also provides context for the highly downregulated uncharacterized protein we have identified as fucolectin-like. While the role of lectins is not fully understood in fish physiology (Elumalai et al., 2019), they likely play an important role in the development of microtubule networks in response to increased salinity. Binding sites have been identified on exposed gill epithelium which interact with the lectins wheat germ agglutinin (WGA), peanut lectin agglutinin (PNA), and concanacalvin A (ConA) (Hirose et al., 2003). WGA and PNA only react with FW specific ionocytes in O. mossambicus (WGA) (Tsai \& Hwang, 1998a) and Oncorhynchus mykiss (PNA) (Goss et al., 2001). WGA exposure was shown to stimulate $\mathrm{Ca}^{+}$ion uptake in $O$. mossambicus and promote microtubule network formation, and binding was more prevalent in $O$. mossambicus adapted to $\mathrm{Ca}^{+}$deficient water (Tsai \& Hwang, 1998b). The uncharacterized protein, along with rhamnose binding lectin which was also one of the most highly downregulated proteins in our data set, may be involved in changing the composition of tubulin-based cell structures, likely to reduce $\mathrm{Ca}^{+}$uptake. This would help control internal ion concentration and impact cell-cell adhesions through cadherin binding, which is also impacted by the high upregulation of $\delta$-catenin 1 .

\section{Conclusions}

This study presents a novel experimental design combined with an innovative research tool for systems-level analyses of molecular phenotypes (DIA-LCMS2). Specific organismal phenotypes (blood osmolality, body condition, feeding rate) were found to correlate well with extreme salinity stress in O. mossambicus . The rate-independent salinity maximum and critical threshold salinity were determined using a comprehensive set of acclimations and a generalized protocol that is reproducible for other species. The DIA-LCMS2 approach was shown to reveal comprehensive molecular phenotypes in ecologically relevant samples. The data generated in this study were used to produce protein networks which elucidate the mechanisms of ionic and mitochondrial protein regulation in response to hypersalinity in general and with respect to the critical threshold. These networks reveal novel information regarding the modulation of energy metabolism, cell adhesion, and cell structure, which includes functional annotation of previously uncharacterized proteins.

\section{Acknowledgements:}

This investigation was supported by the National Science Foundation (NSF-BSF) Grant IOS-1656371 to DK, the US-Israel Binational Agricultural Research and Development Fund (BARD) Grant (IS-5358-21) to DK, and AES projects CA-D-ASC-7690-H, CA-D-ASC-7624-RR, and CA-D-ASC-2667-RR to DK.

\section{References:}

Abbatiello, S., Ackermann, B. L., Borchers, C., Bradshaw, R. A., Carr, S. A., Chalkley, R., Choi, M., Deutsch, E., Domon, B., Hoofnagle, A. N., Keshishian, H., Kuhn, E., Liebler, D. C., MacCoss, M., MacLean, B., Mani, D. R., Neubert, H., Smith, D., Vitek, O., \& Zimmerman, L. (2017). New Guidelines for Publication of Manuscripts Describing Development and Application of Targeted Mass Spectrometry Measurements of Peptides and Proteins. Molecular \& Cellular Proteomics : MCP , 16 (3), 327-328.

Amoudi, M. A., El-Sayed, A.-F. M., \& El-Ghobashy, A. (1996). Effects of Thermal and Thermo-Haline Shocks on Survival and Osmotic Concentration of the Tilapias Oreochromis mossambicus and Oreochromis aureus $\times$ Oreochromis niloticus Hybrids. Journal of the World Aquaculture Society , 27 (4), 456-461. https://doi.org/10.1111/j.1749-7345.1996.tb00630.x

Avella, M., Berhaut, J., \& Bornancin, M. (1993). Salinity tolerance of two tropical fishes, Oreochromis aureus and O. niloticus. I. Biochemical and morphological changes in the gill epithelium. Journal of Fish Biology, 
42 (2), 243-254. https://doi.org/10.1111/j.1095-8649.1993.tb00325.x

Basiao, Z. U., Eguia, R. V., \& Doyle, R. W. (2005). Growth response of Nile tilapia fry to salinity stress in the presence of an 'internal reference' fish. Aquaculture Research , 36 (7), 712-720. https://doi.org/10.1111/j.1365-2109.2005.01283.x

Bazil, J. N., Beard, D. A., \& Vinnakota, K. C. (2016). Catalytic Coupling of Oxidative Phosphorylation, ATP Demand, and Reactive Oxygen Species Generation. Biophysical Journal , 110 (4), 962-971. https://doi.org/10.1016/j.bpj.2015.09.036

Benjamini, Y., \& Hochberg, Y. (1995). Controlling the false discovery rate: A practical and powerful approach to multiple testing. Journal of the Royal Statistical Society. Series B (Methodological) , 57 (1), 289-300.

Blackburn, J. (1987). Revised procedure for the 24-hour seawater challenge test to measure seawater adaptability of juvenile.Canadian Technical Report of Fisheries and Aquatic Sciences ,1515 . https://ci.nii.ac.jp/naid/10005103917/

Bœuf, G., \& Payan, P. (2001). How should salinity influence fish growth? Comparative Biochemistry and Physiology Part C: Toxicology 83 Pharmacology , 130 (4), 411-423. https://doi.org/10.1016/S15320456(01)00268-X

Brett, J. R. (1956). Some Principles in the Thermal Requirements of Fishes. The Quarterly Review of Biology , 31 (2), 75-87. https://doi.org/10.1086/401257

Choi, M., Chang, C. Y., Clough, T., Broudy, D., Killeen, T., MacLean, B., \& Vitek, O. (2014). MSstats: An R package for statistical analysis of quantitative mass spectrometry-based proteomic experiments.Bioinformatics , 30 (17), 2524-2526. https://doi.org/10.1093/bioinformatics/btu305

Christensen, E. A. F., Grosell, M., \& Steffensen, J. F. (2019). Maximum salinity tolerance and osmoregulatory capabilities of European perch Perca fluviatilis populations originating from different salinity habitats. Conservation Physiology , 7 (1), coz004. https://doi.org/10.1093/conphys/coz004

Clarke, B. (1971). Natural Selection and the Evolution of Proteins.Nature , 232 (5311), 487. https://doi.org/10.1038/232487a0

Cui, Y.-W., Zhang, H.-Y., Ding, J.-R., \& Peng, Y.-Z. (2016). The effects of salinity on nitrification using halophilic nitrifiers in a Sequencing Batch Reactor treating hypersaline wastewater.Scientific Reports , 6 (1), 24825. https://doi.org/10.1038/srep24825

Davis, B. E., Hansen, M. J., Cocherell, D. E., Nguyen, T. X., Sommer, T., Baxter, R. D., Fangue, N. A., \& Todgham, A. E. (2019). Consequences of temperature and temperature variability on swimming activity, group structure, and predation of endangered delta smelt. Freshwater Biology , 64 (12), 2156-2175. https://doi.org/10.1111/fwb.13403

Ebhardt, H. A., Root, A., Sander, C., \& Aebersold, R. (2015). Applications of targeted proteomics in systems biology and translational medicine. Proteomics , 15 (18), 3193-3208. https://doi.org/10.1002/pmic.201500004

Edet, U. O., \& Antai, S. P. (2018). Correlation and Distribution of Xenobiotics Genes and Metabolic Activities with Level of Total Petroleum Hydrocarbon in Soil, Sediment and Estuary Water in the Niger Delta Region of Nigeria. Asian Journal of Biotechnology and Genetic Engineering , 1-11.

Elliott, M., \& Quintino, V. (2007). The Estuarine Quality Paradox, Environmental Homeostasis and the difficulty of detecting anthropogenic stress in naturally stressed areas. Marine Pollution Bulletin ,54 (6), 640-645. https://doi.org/10.1016/j.marpolbul.2007.02.003

Elumalai, P., Rubeena, A. S., Arockiaraj, J., Wongpanya, R., Cammarata, M., Ring $\varnothing$, E., \& Vaseeharan, B. (2019). The Role of Lectins in Finfish: A Review. Reviews in Fisheries Science 85 Aquaculture ,27 (2), 152-169. https://doi.org/10.1080/23308249.2018.1520191 
Evans, Piermarini, P. M., \& Choe, K. P. (2005). The Multifunctional Fish Gill: Dominant Site of Gas Exchange, Osmoregulation, Acid-Base Regulation, and Excretion of Nitrogenous Waste. Physiological Reviews , 85 (1), 97-177. https://doi.org/10.1152/physrev.00050.2003

Fiol, D. F., Sanmarti, E., Lim, A. H., \& Kültz, D. (2011). A novel GRAIL E3 ubiquitin ligase promotes environmental salinity tolerance in euryhaline tilapia. Biochimica et Biophysica Acta (BBA) - General Subjects , 1810 (4), 439-445. https://doi.org/10.1016/j.bbagen.2010.11.005

Fridman, S., Rana, K. J., \& Bron, J. E. (2013). Morphological and ultrastructural characterization of ionoregulatory cells in the teleost oreochromis niloticus following salinity challenge combining complementary confocal scanning laser microscopy and transmission electron microscopy using a novel prefixation immunogold labeling technique. Microscopy Research and Technique , 76 (10), 1016-1024. https://doi.org/10.1002/jemt.22262

Fuadi, A. A., Hasly, I. R. J., Azkia, L. I., \& Irham, M. (2021). Response of tilapia (Oreochromis niloticus) behaviour to salinity differences: A laboratory scale study. IOP Conference Series: Earth and Environmental Science ,674 (1), 012060. https://doi.org/10.1088/1755-1315/674/1/012060

Gardell, A. M., Yang, J., Sacchi, R., Fangue, N. A., Hammock, B. D., \& Kültz, D. (2013). Tilapia (Oreochromis mossambicus) brain cells respond to hyperosmotic challenge by inducing myo-inositol biosynthesis. Journal of Experimental Biology , 216 (24), 4615-4625. https://doi.org/10.1242/jeb.088906

Goss, G. G., Adamia, S., \& Galvez, F. (2001). Peanut lectin binds to a subpopulation of mitochondriarich cells in the rainbow trout gill epithelium. American Journal of Physiology-Regulatory, Integrative and Comparative Physiology, 281 (5), R1718-R1725. https://doi.org/10.1152/ajpregu.2001.281.5.R1718

Hiroi, J., McCormick, S. D., Ohtani-Kaneko, R., \& Kaneko, T. (2005). Functional classification of mitochondrion-rich cells in euryhaline Mozambique tilapia (Oreochromis mossambicus) embryos, by means of triple immunofluorescence staining for $\mathrm{Na}+/ \mathrm{K}+$-ATPase, $\mathrm{Na}+/ \mathrm{K}+/ 2 \mathrm{Cl}$ - cotransporter and CFTR anion channel. Journal of Experimental Biology, 208 (11), 2023-2036. https://doi.org/10.1242/jeb.01611

Hirose, S., Kaneko, T., Naito, N., \& Takei, Y. (2003). Molecular biology of major components of chloride cells. Comparative Biochemistry and Physiology Part B: Biochemistry and Molecular Biology ,136 (4), 593-620. https://doi.org/10.1016/S1096-4959(03)00287-2

Inokuchi, M., Hiroi, J., Watanabe, S., Hwang, P.-P., \& Kaneko, T. (2009). Morphological and functional classification of ion-absorbing mitochondria-rich cells in the gills of Mozambique tilapia.Journal of Experimental Biology , 212 (7), 1003-1010. https://doi.org/10.1242/jeb.025957

Inokuchi, M., \& Kaneko, T. (2012). Recruitment and degeneration of mitochondrion-rich cells in the gills of Mozambique tilapia Oreochromis mossambicus during adaptation to a hyperosmotic environment. Comparative Biochemistry and Physiology Part A: Molecular 83 Integrative Physiology , 162 (3), 245251. https://doi.org/10.1016/j.cbpa.2012.03.018

Iwama, G. K., Takemura, A., \& Takano, K. (1997). Oxygen consumption rates of tilapia in fresh water, sea water, and hypersaline sea water.Journal of Fish Biology , 51 (5), 886-894. https://doi.org/10.1111/j.10958649.1997.tb01528.x

Kammerer, B. D., Cech, J. J., \& Kültz, D. (2010). Rapid changes in plasma cortisol, osmolality, and respiration in response to salinity stress in tilapia (Oreochromis mossambicus). Comparative Biochemistry and Physiology Part A: Molecular 83 Integrative Physiology , 157 (3), 260-265. https://doi.org/10.1016/j.cbpa.2010.07.009

Karnaky. (1986). Structure and Function of the Chloride Cell of Fundulus heteroclitus and Other Teleosts1. American Zoologist ,26 (1), 209-224. https://doi.org/10.1093/icb/26.1.209

Karnaky, K. J., Jr, Ernst, S. A., \& Philpott, C. W. (1976). Teleost chloride cell. I. Response of pupfish Cyprinodon variegatus gill $\mathrm{Na}, \mathrm{K}$-ATPase and chloride cell fine structure to various high salinity environments. 
Journal of Cell Biology , 70 (1), 144-156. https://doi.org/10.1083/jcb.70.1.144

Keerthikumar, S., \& Mathivanan, S. (2017). Proteotypic Peptides and Their Applications. Methods in Molecular Biology (Clifton, N.J.) ,1549 , 101-107. https://doi.org/10.1007/978-1-4939-6740-7_8

Kültz, D., Fiol, D., Valkova, N., Gomez-Jimenez, S., Chan, S. Y., \& Lee, J. (2007). Functional genomics and proteomics of the cellular osmotic stress response in "non-model" organisms. The Journal of Experimental Biology , 210 (Pt 9), 1593-1601. https://doi.org/10.1242/jeb.000141

Kültz, D., Jürss, K., \& Jonas, L. (1995). Cellular and epithelial adjustments to altered salinity in the gill and opercular epithelium of a cichlid fish (Oreochromis mossambicus). Cell and Tissue Research, 279 (1), 65-73. https://doi.org/10.1007/BF00300692

Kültz, D., Li, J., Gardell, A., \& Sacchi, R. (2013). Quantitative Molecular Phenotyping of Gill Remodeling in a Cichlid Fish Responding to Salinity Stress. Molecular \& Cellular Proteomics , 12 (12), 3962-3975. https://doi.org/10.1074/mcp.M113.029827

Kültz, D., Li, J., Paguio, D., Pham, T., Eidsaa, M., \& Almaas, E. (2016). Population-specific renal proteomes of marine and freshwater three-spined sticklebacks. Journal of Proteomics , 135 , 112-131. https://doi.org/10.1016/j.jprot.2015.10.002

Kültz, D., \& Onken, H. (1993). Long-term acclimation of the teleost Oreochromis mossambicus to various salinities: Two different strategies in mastering hypertonic stress. Marine Biology , 117 (3), 527-533. https://doi.org/10.1007/BF00349328

Langston, J. N., Schofield, P. J., Hill, J. E., \& Loftus, W. F. (2010). Salinity Tolerance of the African Jewelfish Hemichromis letourneuxi, a Non-native Cichlid in South Florida (USA). Copeia ,2010 (3), 475480. https://doi.org/10.1643/CP-09-069

Laskar, A. A., \& Younus, H. (2019). Aldehyde toxicity and metabolism: The role of aldehyde dehydrogenases in detoxification, drug resistance and carcinogenesis. Drug Metabolism Reviews , 51 (1), 42-64. https://doi.org/10.1080/03602532.2018.1555587

Leary, S., Pharmaceuticals, F., Underwood, W., Anthony, R., Cartner, S., Johnson, C. L., \& Patterson-Kane, E. (2020). AVMA Guidelines for the Euthanasia of Animals: 2020 Edition . 121.

Lee, T. H., Hwang, P. P., Shieh, Y. E., \& Lin, C. H. (2000). The relationship between 'deep-hole' mitochondria-rich cells and salinity adaptation in the euryhaline teleost, Oreochromis mossambicus. Fish Physiology and Biochemistry, 23 (2), 133-140. https://doi.org/10.1023/A:1007818631917

Lewis, E. L., \& Perkin, R. G. (1978). Salinity: Its definition and calculation. Journal of Geophysical Research: Oceans ,83 (C1), 466-478. https://doi.org/10.1029/JC083iC01p00466

Li, J., Levitan, B., Gomez-Jimenez, S., \& Kültz, D. (2018). Development of a Gill Assay Library for Ecological Proteomics of Threespine Sticklebacks ( Gasterosteus aculeatus ). Molecular $\&$ Cellular Proteomics , 17 (11), 2146-2163. https://doi.org/10.1074/mcp.RA118.000973

Mularoni, L., Ledda, A., Toll-Riera, M., \& Albà, M. M. (2010). Natural selection drives the accumulation of amino acid tandem repeats in human proteins. Genome Research , 20 (6), 745-754. https://doi.org/10.1101/gr.101261.109

Panfili, J., Mbow, A., Durand, J. D., Diop, K., Diouf, K., Thior, D., Ndiaye, P., \& Lae, R. (2004). Influence of salinity on the life-history traits of the West African black-chinned tilapia (Sarotherodon melanotheron): Comparison between the Gambia and Saloum estuaries.Aquatic Living Resources , 17 (1), 65-74. https://doi.org/10.1051/alr:2004002

Pino, L. K., Searle, B. C., Bollinger, J. G., Nunn, B., MacLean, B., \& MacCoss, M. J. (2017). The Skyline ecosystem: Informatics for quantitative mass spectrometry proteomics. Mass Spectrom Rev ,39 (3), 229-244. https://doi.org/10.1002/mas.21540 
Pörtner, H.-O. (2010). Oxygen- and capacity-limitation of thermal tolerance: A matrix for integrating climate-related stressor effects in marine ecosystems. Journal of Experimental Biology ,213 (6), 881-893. https://doi.org/10.1242/jeb.037523

Reiter, L., Rinner, O., Picotti, P., Huttenhain, R., Beck, M., Brusniak, M. Y., Hengartner, M. O., \& Aebersold, R. (2011). mProphet: Automated data processing and statistical validation for large-scale SRM experiments. Nat Methods , 8 (5), 430-435. https://doi.org/10.1038/nmeth.1584

Richards, J. G., Semple, J. W., Bystriansky, J. S., \& Schulte, P. M. (2003). Na+/K+-ATPase $\alpha$-isoform switching in gills of rainbow trout (Oncorhynchus mykiss) during salinity transfer. Journal of Experimental Biology , 206 (24), 4475-4486. https://doi.org/10.1242/jeb.00701

Ronkin, D., Seroussi, E., Nitzan, T., Doron-Faigenboim, A., \& Cnaani, A. (2015). Intestinal transcriptome analysis revealed differential salinity adaptation between two tilapiine species. Comparative Biochemistry and Physiology Part D: Genomics and Proteomics , 13 , 35-43. https://doi.org/10.1016/j.cbd.2015.01.003

Root, L., Campo, A., MacNiven, L., Con, P., Cnaani, A., \& Kültz, D. (2021a). Nonlinear effects of environmental salinity on the gill transcriptome versus proteome of Oreochromis niloticus modulate epithelial cell turnover. Genomics , 113 (5), 3235-3249. https://doi.org/10.1016/j.ygeno.2021.07.016

Root, L., Campo, A., MacNiven, L., Con, P., Cnaani, A., \& Kültz, D. (2021b). A data-independent acquisition (DIA) assay library for quantitation of environmental effects on the kidney proteome of Oreochromis niloticus. Molecular Ecology Resources , 21 (7), 2486-2503. https://doi.org/10.1111/1755-0998.13445

Rosen, M. B., Schmid, J. R., Corton, J. C., Zehr, R. D., Das, K. P., Abbott, B. D., \& Lau, C. (2010). Gene Expression Profiling in Wild-Type and PPAR $\alpha$-Null Mice Exposed to Perfluorooctane Sulfonate Reveals PPAR $\alpha$-Independent Effects. PPAR Research , 2010 , 794739. https://doi.org/10.1155/2010/794739

Sardella, B. A. (2004). Physiological, biochemical and morphological indicators of osmoregulatory stress in 'California' Mozambique tilapia (Oreochromis mossambicus x O. urolepis hornorum) exposed to hypersaline water. Journal of Experimental Biology, 207 (8), 1399-1413. https://doi.org/10.1242/jeb.00895

Sardella, B. A., \& Brauner, C. J. (2007). The Osmo-respiratory Compromise in Fish: The Effects of Physiological State and the Environment. In Fish Respiration and Environment (p. chapter 8). CRC Press.

Schultz, E., \& McCormick, S. (2012). Euryhalinity in an Evolutionary Context. In Euryhaline Fishes (Vol. 32, pp. 477-533). https://opencommons.uconn.edu/eeb_articles/29

Sokolova, I. M., Frederich, M., Bagwe, R., Lannig, G., \& Sukhotin, A. A. (2012). Energy homeostasis as an integrative tool for assessing limits of environmental stress tolerance in aquatic invertebrates. Marine Environmental Research , 79 , 1-15. https://doi.org/10.1016/j.marenvres.2012.04.003

Somero, G., Lockwood, B., Tomanek, L. (2016). Biochemical Adaptation, Response to Environmental Challenges from Life's Origins to the Anthropocene. Sinauer Associates, an imprint of Oxford University Press. //global.oup.com/ukhe/product/biochemical-adaptation-9781605355641

Speare, D. J., MacNair, N., \& Hammell, K. L. (1995). Demonstration of tank effect on growth indices of juvenile rainbow trout (Oncorhynchus mykiss) during an ad libitum feeding trial. American Journal of Veterinary Research , 56 (10), 1372-1379.

Szklarczyk, D., Gable, A. L., Lyon, D., Junge, A., Wyder, S., Huerta-Cepas, J., Simonovic, M., Doncheva, N. T., Morris, J. H., Bork, P., Jensen, L. J., \& Mering, C. von. (2019). STRING v11: Protein-protein association networks with increased coverage, supporting functional discovery in genome-wide experimental datasets.Nucleic Acids Research , 47 (D1), D607-D613. https://doi.org/10.1093/nar/gky1131

Tipsmark, C. K., Breves, J. P., Seale, A. P., Lerner, D. T., Hirano, T., \& Grau, E. G. (2011). Switching of $\mathrm{Na}+, \mathrm{K}+$-ATPase isoforms by salinity and prolactin in the gill of a cichlid fish. The Journal of Endocrinology , 209 (2), 237-244. https://doi.org/10.1530/joe-10-0495 
Tsai, J. C., \& Hwang, P. P. (1998a). The wheat germ agglutinin binding sites and development of the mitochondria-rich cells in gills of tilapia (Oreochromis mossambicus). Fish Physiology and Biochemistry,19 (1), 95-102. https://doi.org/10.1023/A:1007766531264

Tsai, J. C., \& Hwang, P. P. (1998b). Effects of wheat germ agglutinin and colchicine on microtubules of the mitochondria-rich cells and Ca2+ uptake in tilapia (Oreochromis mossambicus) larvae. Journal of Experimental Biology , 201 (15), 2263-2271. https://doi.org/10.1242/jeb.201.15.2263

Watanabe, W. O., Kuo, C.-M., \& Huang, M.-C. (1985). The ontogeny of salinity tolerance in the tilapias Oreochromis aureus, O. niloticus, and an O. mossambicus $\times$ O. niloticus hybrid, spawned and reared in freshwater. Aquaculture , 47 (4), 353-367. https://doi.org/10.1016/0044-8486(85)90220-0

Whitfield, A. K., Taylor, R. H., Fox, C., \& Cyrus, D. P. (2006). Fishes and salinities in the St Lucia estuarine system-A review.Reviews in Fish Biology and Fisheries , 16 (1), 1-20. https://doi.org/10.1007/s11160-006$0003-\mathrm{x}$

Yamaguchi, T., Gi, M., Fujioka, M., Tago, Y., Kakehashi, A., \& Wanibuchi, H. (2019). A chronic toxicity study of diphenylarsinic acid in the drinking water of C57BL/6J mice for 52 weeks. Journal of Toxicologic Pathology , 32 (3), 127-134. https://doi.org/10.1293/tox.2018-0067

Zeng, L., Li, X., Preusch, C. B., He, G. J., Xu, N., Cheung, T. H., Qu, J., \& Mak, H. Y. (2021). Nuclear receptors NHR-49 and NHR-79 promote peroxisome proliferation to compensate for aldehyde dehydrogenase deficiency in C. elegans. PLOS Genetics , 17 (7), e1009635. https://doi.org/10.1371/journal.pgen.1009635

Data Accessibility Statement:

All proteomics data and metadata have been deposited and are publicly accessible at the following repositories MassIVE (MSV000085745) and ProteomeXchange (PXD020364) and ProteomeXchange (PXD020064) for all DDA data, and PanoramaPublic (https://panoramaweb.org/lr03.url) for all DIA data (including the DIA assay library).

Author Contributions:

LR and DK designed research; LR performed research; DK contributed new reagents and analytical tools; LR and DK analyzed data; LR wrote the paper; DK edited the paper

Figures:

Figure 1: Survival and organismal phenotypes during hypersalinity acclimation. a) Percentage of fish remaining versus salinity following constant daily salinity increase at five rates of increase $(\mathrm{n}=8)$. $\mathbf{b})$ Percentage of fish remaining over time at constant salinity after acclimation to four hypersaline conditions $(\mathrm{n}=12$ at $105 / 95 / 85 \mathrm{~g} / \mathrm{kg}, \mathrm{n}=48$ at $75 \mathrm{~g} / \mathrm{kg}$ ). Lines in $\mathrm{A}$ and $\mathrm{B}$ follow logistic functions. c) Blood osmolality values for five 14-day acclimations after 24 hours at the target salinity $(\mathrm{n}=6$ except at $75 \mathrm{~g} / \mathrm{kg}$ with $\mathrm{n}=4)$ and following extended exposure for 12 weeks $(75 \mathrm{~g} / \mathrm{kg}, \mathrm{n}=8)$ and at MP $(85 / 105 \mathrm{~g} / \mathrm{kg}, \mathrm{n}=6)$. d) Body condition for the same treatments as $\mathbf{c}$. Letters in $\mathrm{C}$ and $\mathrm{D}$ were assigned using a post-hoc Tukey test following one-way ANOVA. e) Normalized Feeding for the same treatments as C and D except the 12-week experiment. 


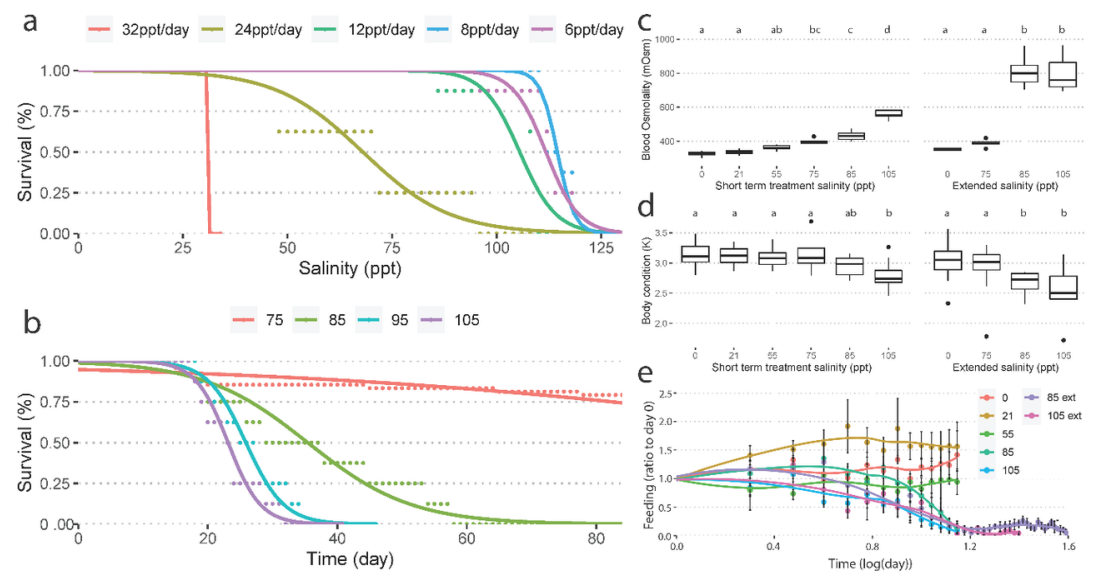




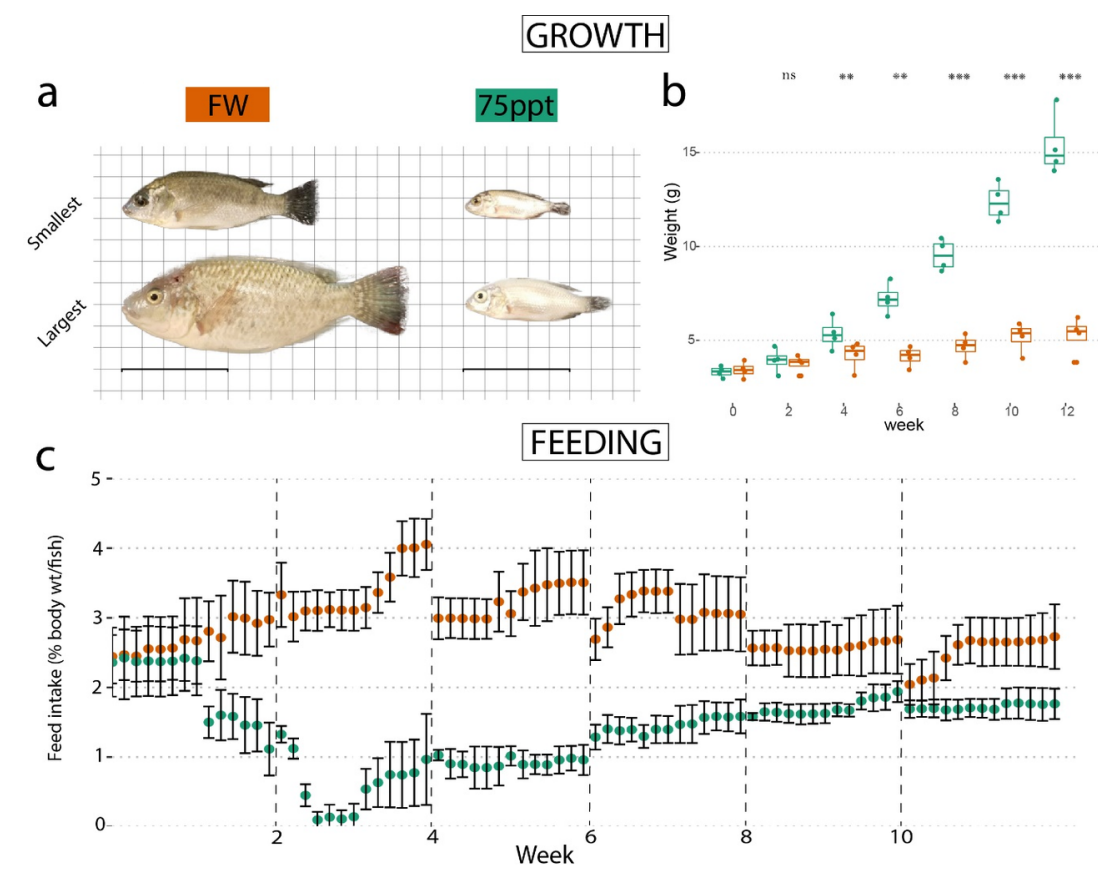

Figure 2: Growth and feeding during 12-week exposure to $75 \mathrm{~g} / \mathrm{kg}$ salinity. a) Size comparison of smallest and largest fish in the freshwater and $75 \mathrm{~g} / \mathrm{kg}$ treatment at the end of the experiment. b) Weight gain for FW control and at $75 \mathrm{~g} / \mathrm{kg}$, with comparison between treatments. Significance was determined using Kruskal-Wallis test by ranks with "ns"- not significant, "**" $\mathrm{p}<0.05$, “**" - $\mathrm{p}<0.005$, “***" - $<<0.0005$. c) Percent of fish body weight consumed daily over the course of the experiments, with weekly weighing identified by dashed vertical lines.

Figure 3 : Salinity effects on the gill proteome for five treatments. a) Volcano plots for each treatment with $\log 2$ (Fold Change) plotted against $\log 10$ (p-value). $\mathrm{n}=8$ for 85 and $105 \mathrm{~g} / \mathrm{kg} 14$-day acclimation and $75 \mathrm{~g} / \mathrm{kg}$ extended treatment, and $\mathrm{n}=6$ for extended 85 and $105 \mathrm{~g} / \mathrm{kg}$ treatments. Significantly upregulated proteins are plotted in red with the total number of sig. upregulated proteins labelled, and significantly downregulated proteins are in blue. b) Top significantly regulated proteins with the FC difference with controls shown. Redder boxes are more highly upregulated while bluer boxes are more highly downregulated. c) Overlap in all significantly regulated proteins between five treatments with the number of proteins in each segment labelled. 

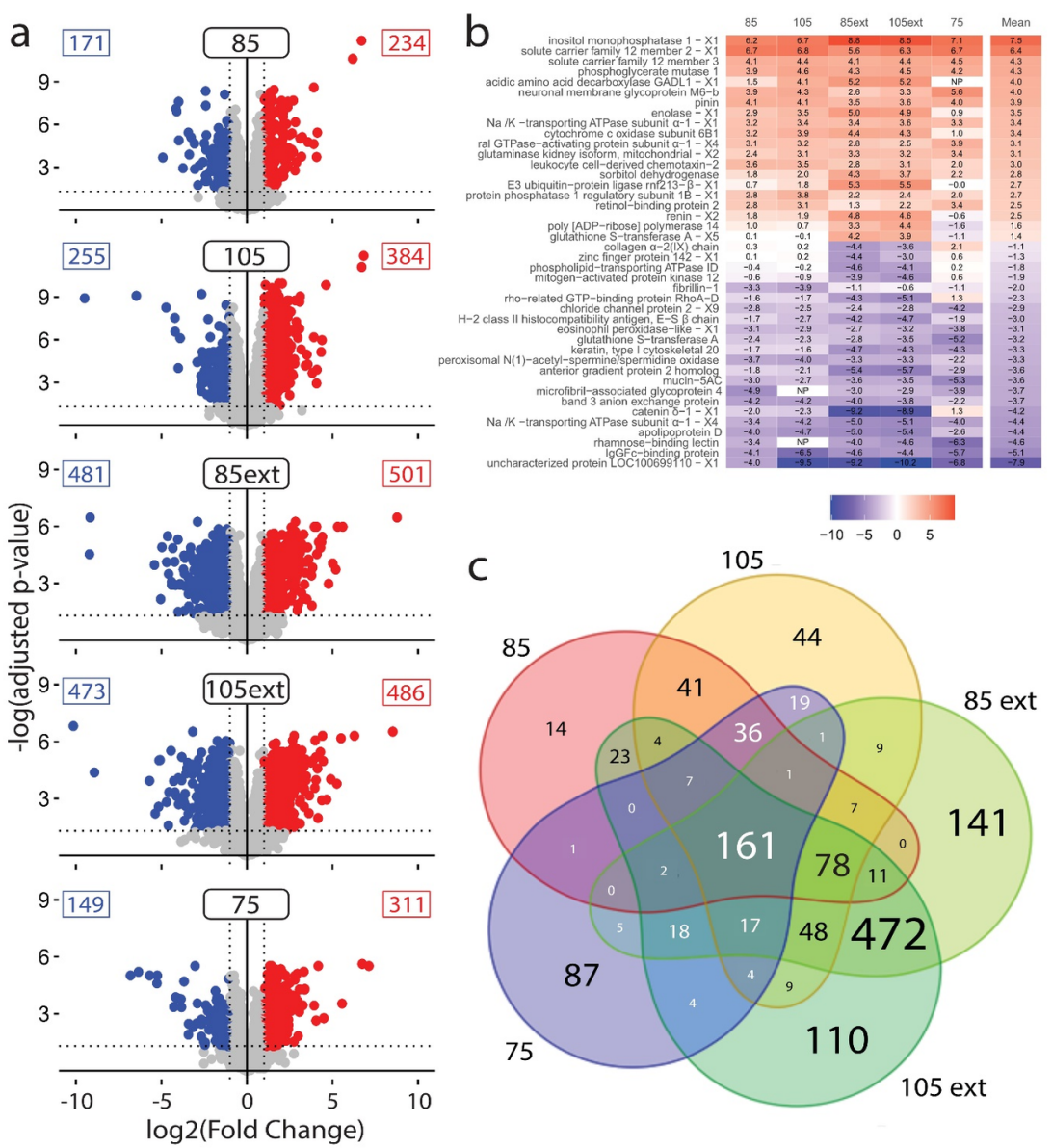

Figure 4: STRING network showing all proteins which were significantly regulated in all treatments. Nodes represent one STRING protein ID and edges represent a connection based on proteinprotein

interactions including known or predicted interactions based on published literature. Solid lines connect all members of one cluster, while dashed lines indicate connections that are not strong enough to be included in the same cluster based on a Markov Cluster inflation factor of 3. Central members of the Electron Transport Chain (red), glycolysis (green), and citric acid cycle (yellow) are indicated, along with specific proteins labelled. 


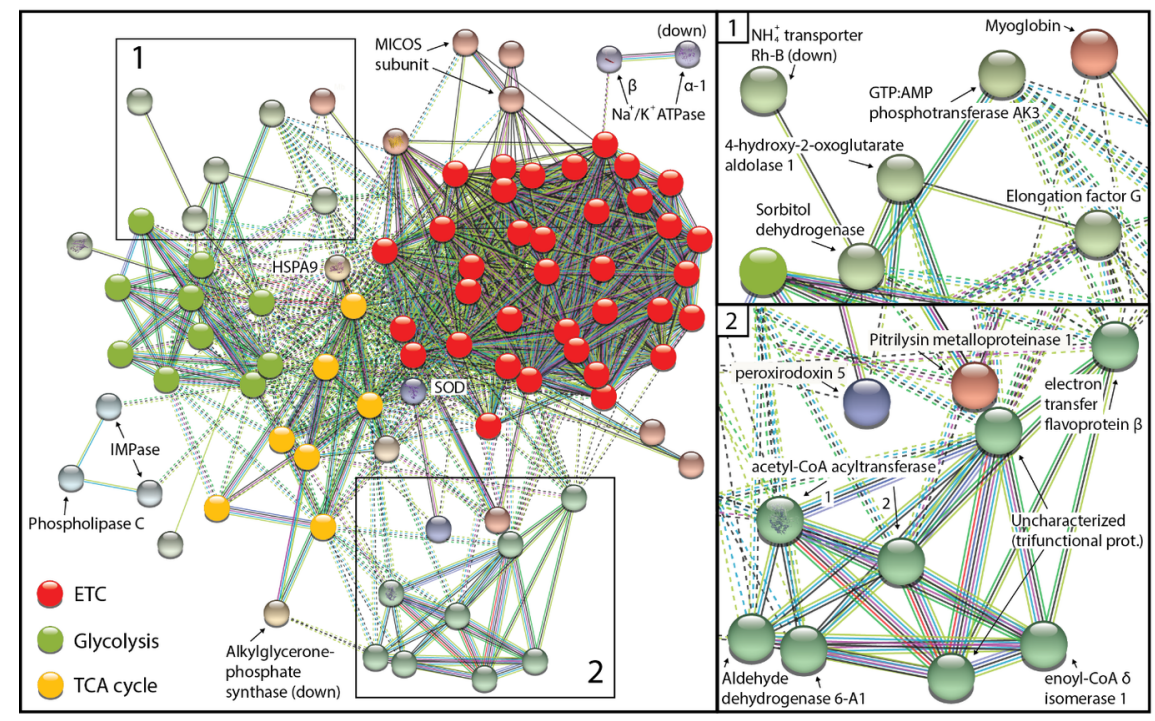

Figure 5: STRING networks for pejus and pessimum stress stages and network and correlation graphs of proteins with expression patterns highly correlated with blood osmolality. a) Networks with more than three nodes for all significantly regulated proteins found in the 12-week exposure to $75 \mathrm{~g} / \mathrm{kg}$ salinity representing pejus level salinity stress. Protein names in red were upregulated, those in blue were downregulated, and those outlined in red were upregulated in this treatment while being significantly downregulated in extended exposures to MP at $85 \mathrm{~g} / \mathrm{kg}$ and $/$ or $105 \mathrm{~g} / \mathrm{kg}$. b) Networks with more than three nodes for significantly regulated proteins found in all four pessimum level salinity stress treatments (14-day acclimation and extended exposure to $85 \mathrm{~g} / \mathrm{kg}$ and $105 \mathrm{~g} / \mathrm{kg}$ ). Legend indicates the evidence used to connect protein nodes in each network. c) STRING network with symbols and colors corresponding with line graphs of Serpin family proteins, proteins in the "focal adhesion" KEGG pathway, and other proteins in the network. Network was constructed from proteins linked with more than two other nodes that have correlation coefficient $\mathrm{r}^{2}>0.9$ with protein fold change (FC) versus blood osmolality (mOsm) FC of treatment over control. 


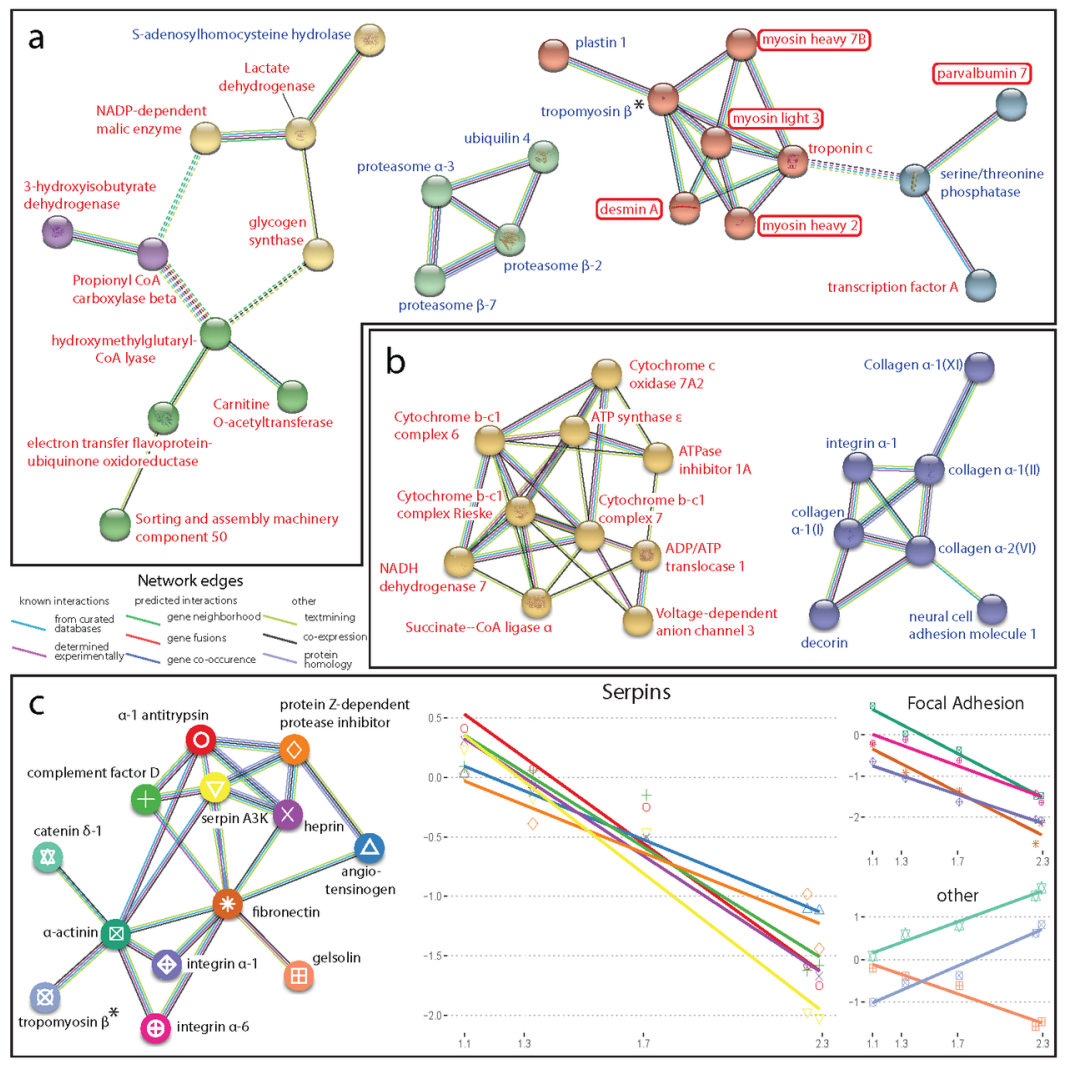

Supplementary figures:

Supplementary figure 1 : Properties of a O. mossambicusgill epithelium DIA assay library relative to the corresponding raw spectral library. The initial spectral library (SL) represents over 16,000 proteins, 139,000 precursors, and 864,000 transitions. Ten QC filters were applied to create the DIA assay library containing 3024 proteins (A), 13,847 peptides (B) and precursors (C), and 68,586 transitions (D). Most proteins are represented by at least 2 diagnostic peptides. The remainder (825) was identified by at least 2 unique peptides but only 1 remains after applying all DIA QC filters. The initial bar labeled SL depicts data for the raw spectral library and final bar (step 10) depicts data for the DIA assay library. Library filtration steps one to six are explained in the text. (E), Frequency distributions of fragment ion types represented in the final DIA assay library. b+ ions are fragments which extend from the N-terminus of the peptide and $\mathrm{y}+$ ions extend from the C-terminus i.e. a 3 fragment ion denominator member contains the first three peptides for $a \mathrm{~b}+$ ion and the last three for a $\mathrm{y}+$ ion. (F), Frequency distribution for the number of peptides per 
protein in the DIA assay library. The data were generated with Skyline 20.0 (MacCoss Lab., University of Washington).

Supplementary figure 2: Quality control parameters summarized for all samples in five treatments analyzed in this study. A) The mean mass error ( $\mathrm{ppm}$ ) for all transitions present in the final assay library in the 14 -day $85 \mathrm{~g} / \mathrm{kg}$ treatment. Other treatments shown are 14 -day $105 \mathrm{~g} / \mathrm{kg}(\mathrm{E})$, extended $85 \mathrm{~g} / \mathrm{kg}(\mathrm{I})$, extended $105 \mathrm{~g} / \mathrm{kg}(\mathrm{M})$, and 12 -week $75 \mathrm{~g} / \mathrm{kg}(\mathrm{Q})$. B) Retention time for the 14-day $85 \mathrm{~g} / \mathrm{kg}$ treatment. reproducibility for all transitions in all samples analyzed in this study was very high $\left(\mathrm{r}^{2}=1.0\right)$. Other treatments shown are 14-day $105 \mathrm{~g} / \mathrm{kg}(\mathrm{F})$, extended $85 \mathrm{~g} / \mathrm{kg}(\mathrm{J})$, extended $105 \mathrm{~g} / \mathrm{kg}(\mathrm{N})$, and 12 -week $75 \mathrm{~g} / \mathrm{kg}(\mathrm{R})$. C) Fold change $(\mathrm{FC})$ and coefficient of variation $(\mathrm{CV})$ depending on number of biological replicates at a statistical power of 0.8 and false discovery rate (FDR) of $1 \%$ in the 14 -day $85 \mathrm{~g} / \mathrm{kg}$ treatment. Other treatments shown are 14-day $105 \mathrm{~g} / \mathrm{kg}(\mathrm{G})$, extended $85 \mathrm{~g} / \mathrm{kg}(\mathrm{K})$, extended $105 \mathrm{~g} / \mathrm{kg}(\mathrm{O})$, and 12 -week $75 \mathrm{~g} / \mathrm{kg}(\mathrm{S})$. D) mProphet Q values for all transitions in all samples in the 14 -day $85 \mathrm{~g} / \mathrm{kg}$ treatment. Other treatments shown are 14-day $105 \mathrm{~g} / \mathrm{kg}(\mathrm{H})$, extended $85 \mathrm{~g} / \mathrm{kg}(\mathrm{L})$, extended $105 \mathrm{~g} / \mathrm{kg}(\mathrm{P})$, and 12 -week $75 \mathrm{~g} / \mathrm{kg}(\mathrm{T})$. Figures were generated with Skyline 20.0 (including MSstats and mProphet) software (MacCoss Lab., University of Washington).

Supplementary figure 3: Alignment and distance tree of full uncharacterized protein sequence and one repeat of the sequence. A) Alignment of the full sequence of the uncharacterized protein LOC100699110 X1 with all named proteins in the top 100 blastp results based on E-value using the non-redundant protein sequence database of the NCBI and no specified organism. B) Alignment of the 143 amino acid (AA) repeat segment using the same parameters as in A. C) Distance tree of results from A based on BLAST computed pairwise alignment with evolutionary distance modeled as the expected fraction of AA substitutions per site based on the fraction of mismatched AAs in the region following ${ }^{68}$. D) Distance tree of results for 143 AA repeat results. E) Beginning section of the amino acid sequence showing peptide coverage from the DIA assay library. Repeat AA segment is highlighted.

Supplementary tables:

Supplementary table 1 : Fold Change and p-values for all proteins in all treatments

Supplementary table 2 : Correlation of protein fold change with physiological and experimental parameters. Crosses indicate correlation coefficient $\left(\mathrm{r}^{2}\right)$ greater than 0.9. Significant regulation indicated by letters representing treatment as follows: A-14-day $85 \mathrm{~g} / \mathrm{kg}$, B-14-day $105 \mathrm{~g} / \mathrm{kg}$, C-extended $85 \mathrm{~g} / \mathrm{kg}$, D-extended $105 \mathrm{~g} / \mathrm{kg}, \mathrm{E}-12$-week $75 \mathrm{~g} / \mathrm{kg}$, and representing regulation pattern (U-upregulated, D-downregulated). 